Cite this: Soft Matter, 2014, 10, 5003

\title{
Development of polar order and tilt in lamellar liquid crystalline phases of a bent-core mesogen $\uparrow$
}

\author{
Mohamed Alaasar, ${ }^{\text {*ab }}$ Marko Prehm, ${ }^{a}$ Marco Poppe, ${ }^{a}$ Mamatha Nagaraj, ${ }^{c}$ \\ Jagdish K. Vij ${ }^{\complement}$ and Carsten Tschierske*a
}

A new bent-core mesogen combining a 4-cyanoresorcinol unit with two terephthalate based rod-like wings and terminated by two long alkyl chains, was synthesized and investigated by DSC, XRD, optical, electrooptical and dielectric methods. A series of liquid crystalline phases in the unique sequence SmA$S m A_{(P)}-S m C P_{R}-\left(M_{1} / S m C P_{\alpha}\right)-S m C_{s} P_{A}-S m C_{a}^{\prime} P_{A}-S m C_{a} P_{A}$, mainly distinguished by the degree and mode of correlation of tilt and polar order, was observed. The development of polar order is associated with the emergence of a small tilt $\left(<10^{\circ}\right)$. With decreasing temperature the tilt changes from random (SmA) via synclinic to anticlinic, while the coherence length of the polar domains grows. This small tilt gives rise to an only weak layer coupling which is in competition with the polar coupling and this leads to new modes of self assembly in lamellar phases of bent-core mesogens, among them the $\mathrm{SmCP}_{\mathrm{R}}$ and the $\mathrm{SmCP}_{\alpha}$ phases. The $\mathrm{SmCP}_{\mathrm{R}}$ phase is an only slightly tilted biaxial smectic phase with randomized polar order and the $\mathrm{SmCP}_{\alpha}$. phase is a slightly tilted and antiferroelectric switching, but uniaxial smectic phase. For this phase a regular change of the in-plane polarization vector between the layers by an angle between $>0^{\circ}$ and $<90^{\circ}$ is proposed.

Received 18th March 2014

Accepted 15th May 2014

DOI: $10.1039 / \mathrm{c} 4 \mathrm{sm} 00593 \mathrm{~g}$

www.rsc.org/softmatter compounds for which such polar SmA phases has been reported represent 4-cyanoresorcinol bisbenzoates, with terephthalate based wings $1 / n$ and $2 / n$ (see Scheme 1 ), for which two homologues with the alkoxy chains $\mathrm{R}=\mathrm{OC}_{8} \mathrm{H}_{17}(1 / 8)$ and $\mathrm{R}$ $=\mathrm{OC}_{12} \mathrm{H}_{25}(1 / 12)$ have first been reported by Weissflog et al. ${ }^{9} \mathrm{~A}$ typical feature reported for these compounds is the formation of $\mathrm{SmAP}_{\mathrm{A}}$ phases. We have previously reported a series of orthogonal smectic phases, including $\operatorname{SmAP}_{A}$ and $\operatorname{SmAP}_{R}$ phases for compounds $2 / n$ with alkyl instead of alkoxy chains $\left(\mathrm{R}=\mathrm{C}_{n} \mathrm{H}_{2 n+1}\right){ }^{6}$ For one of these compounds with $n=14(2 / 14)$ an antiferroelectric switching and uniaxial smectic phase ${ }^{12}$ was observed, for which a $\operatorname{SmAP}_{\alpha}$ structure was proposed, where the in-plane polarization direction rotates uniformly from layer to layer by a fixed angle., ${ }^{9,13 a}$

Here we report the mesomorphic properties of a new 4-cyanoresorcinol compound $1 / 14$ with terephthalate based wing groups, having two terminal tetradecyloxy chains $\left(\mathrm{R}=\mathrm{OC}_{14} \mathrm{H}_{29}\right)$ instead of the alkyl chains with the same number of carbon atoms $\left(\mathrm{R}=\mathrm{C}_{14} \mathrm{H}_{29}\right)$ in compound 2/14. It turned out that the phase behaviour of this particular compound is distinct from the related alkyl substituted compound 2/14 and also much more complex than previously reported for the shorter homologues $1 / n$ with $\mathrm{OC}_{8} \mathrm{H}_{17}(1 / 8)$ and $\mathrm{OC}_{12} \mathrm{H}_{25}$ chains $(1 / 12) .{ }^{9}$ The new compound $1 / 14$ with longer alkoxy chains exhibits the unique sequence of eight liquid crystalline phases, shown in Scheme 1. Moreover, formation of tilted smectic phases was observed instead of the orthogonal phases of the previously reported homologues $1 / n(n=8,12)$.
${ }^{a}$ Institute of Chemistry, Martin Luther University Halle-Wittenberg, Kurt Mothes Str. 2, D-06120 Halle (Saale), Germany.E-mail: carsten.tschierske@chemie.uni-halle.de

${ }^{b}$ Department of Chemistry, Faculty of Science, Cairo University, Giza, Egypt. E-mail: malaasar@sci.cu.edu.eg

${ }^{c}$ Department of Electronic and Electrical Engineering, Trinity College, University of Dublin, Dublin 2, Ireland

$\dagger$ Electronic supplementary information (ESI) available. See DOI: $10.1039 / \mathrm{c} 4 \mathrm{sm} 00593 \mathrm{~g}$ 


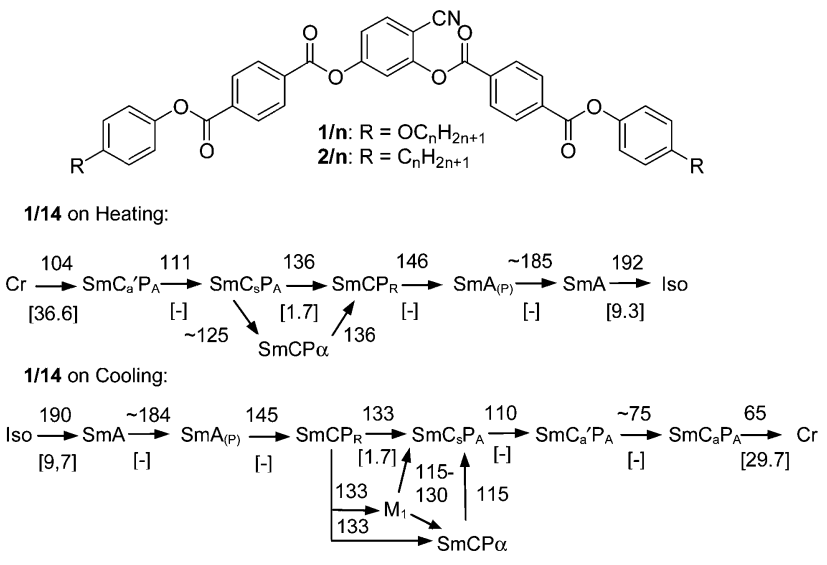

1/8: $\operatorname{Cr} 113 \mathrm{SmAP}_{\mathrm{A}} 144 \mathrm{SmA} 187$ Iso

1/12: $\mathrm{Cr} 106 \mathrm{SmAP}_{\mathrm{A}} 112 \mathrm{SmA} 185$ Iso

2/14: $\mathrm{Cr} 113\left(\mathrm{SmAP}_{\mathrm{A}} 91\right) \mathrm{SmAP}_{\alpha} 108 \mathrm{SmAP}_{\mathrm{R}} 111 \mathrm{SmA} 164$ Iso

\section{List of abbreviations:}

$\mathrm{Cr} \quad$ crystalline solid

SmA nonpolar non-tilted smectic phase

$\mathrm{SmA}_{(P)}$ paraelectric SmA phase with local polar order and showing dielectric reorientation of the polar domains

$S_{\mathrm{S} A P_{\mathrm{R}}}$ uniaxial SmA phase with randomized polar order (in comparison to $\mathrm{SmA}_{(\mathrm{P})}$ the polar domains are larger and polar order and biaxiality can be induced in homeotropic samples under an electric in-plane field with reasonable strength)

$\mathrm{SmCP}_{\mathrm{R}}$ biaxial smectic phase with small tilt $(\mathrm{SmC})$ and randomized polar order

$\mathrm{SmAP}_{A} \quad$ antiferroelectric switching polar SmA phase

$\mathrm{SmAP}_{\alpha} \quad$ antiferroelectric switching SmA phase with a change of the in-plane polarization vectors by the same angle and sign between adjacent layers $^{13}$

$\mathrm{SmCP}_{\alpha} \quad$ antiferroelectric switching slightly tilted, but optically uniaxial SmC phase in which the in-plane polarization vectors change by the same angle and sign between adjacent layers

$\mathrm{SmC}_{S} \mathrm{P}_{\mathrm{A}} \quad$ antiferroelectric switching and synclinic tilted $\mathrm{SmC}$ phase

$\mathrm{SmC}_{\mathrm{a}} \mathrm{P}_{\mathrm{A}}$ antiferroelectric switching $\mathrm{SmC}$ phase composed of $\mathrm{SmC}_{\mathrm{s}} \mathrm{P}_{\mathrm{F}}$ domains with antipolar and anticlinic correlation $\left(\left(\mathrm{SmC}_{\mathrm{S}} \mathrm{P}_{\mathrm{F}}\right)_{\mathrm{a}} \mathrm{P}_{\mathrm{A}}\right)$

$\mathrm{SmC}_{\mathrm{a}} \mathrm{P}_{\mathrm{A}} \quad$ antiferroelectric switching and anticlinic tilted SmC phase

$M_{1} \quad$ optically biaxial and highly viscous mesophase with unknown structure

Iso

isotropic liquid

Scheme 1 Structure of compound 1/14 under investigation herein, its phase sequences on heating and cooling (data were obtained from DSC peak temperatures, see Fig. 1, combined with optical investigations of homeotropic aligned samples between non-treated glass surfaces and electrooptical investigations) and comparison with previously reported structurally related 4-cyanoresorcinols with terephthalate wings (1/8, 1/12 (ref. 9) and 2/14 (ref. 13)), their phases and phase transitions $\left(T /{ }^{\circ} \mathrm{C}, \Delta H / \mathrm{kJ} \mathrm{mol}^{-1}\right.$, values in square brackets) and abbreviations of the phase assignments used herein.

This new compound allows the investigation of the development of polar order and tilt in the smectic phases of bentcore mesogens. It seems that the emergence of polar order is in this case coupled with the emergence of tilt. The tilt is relatively small, which provides an only weak layer coupling and this weak coupling gives rise to new phase structures, namely a weakly tilted biaxial smectic phase with randomized polar order $\left(\mathrm{SmCP}_{\mathrm{R}}\right)$ and a SmC phase with a unique combination of antiferroelectric switching and optical uniaxiality, most probably representing a $\mathrm{SmCP}_{\alpha}$ phase where the in-plane polarization direction rotates from layer to layer by a fixed angle uniformly between adjacent layers. Overall, the unprecedented sequence of a total of eight different LC phase structures, $\operatorname{SmA}_{-} \operatorname{SmA}_{(\mathrm{P})}-$ $\mathrm{SmCP}_{\mathrm{R}}-\left(\mathrm{M}_{1} / \mathrm{SmCP}_{\alpha}\right)-\mathrm{SmC}_{\mathrm{S}} \mathrm{P}_{\mathrm{A}}-\mathrm{SmC}_{\mathrm{a}}^{\prime} \mathrm{P}_{\mathrm{A}}-\mathrm{SmC}_{\mathrm{a}} \mathrm{P}_{\mathrm{A}}$, results from the competition between polar coupling and tilt coupling between the layers. Moreover, the competition between the biaxiality caused by the tilt and by the restricted rotation around the long axis lead to an inversion of birefringence, which is reported here for the first time in a mesophase formed by bentcore molecules. Thus, the present work provides new insights in the complex mechanisms involved in the transition from nonpolar to polar smectic phases.

Because of the large number of slightly different mesophase structures and the relatively complex relations between them, the phase assignment shown and explained in Scheme 1 is used throughout the manuscript right from the beginning. In Sections 3.1-3.6 the investigation by the different methods is described first and in Section 3.7 the different LC phase structures will be analyzed and discussed step-by-step in more detail, explaining and confirming the proposed structures based on combined interpretation of various results given in Sections 3.1-3.6.

\section{Experimental}

\subsection{Synthesis}

The synthetic procedures leading to the target compound are outlined in Scheme S1 in the ESI. $\dagger$ In this procedure 4-cyanoresorcinol was acylated with 4-(4- $n$-tetradecyloxyphenoxycarbonylbenzoyloxy)benzoic acid, which was obtained by esterification of 4-formylbenzoic acid with 4-tetradecyloxyphenol followed by oxidation of $\mathrm{CHO}$ to $\mathrm{COOH}$ (for details see ESI $\dagger)^{14}$

\subsection{Investigation methods}

Investigation of the mesomorphic properties is based on polarizing microscopy (PM), differential scanning calorimetry (DSC), X-ray diffraction (XRD) of surface aligned samples as well as on electrooptical and dielectric experiments.

The mesophase behaviour and transition temperatures of the prepared bent-core molecule was measured using a Mettler FP-82 HT hot stage and control unit in conjunction with a Nikon Optiphot-2 polarizing microscope. The associated enthalpies were obtained from DSC-thermograms which were recorded on a Perkin-Elmer DSC-7, heating and cooling rate: $10 \mathrm{~K} \mathrm{~min}^{-1}$. The electro-optical switching characteristics were examined with the triangular-wave method using a home-made set-up in polyimide coated ITO cells of thickness $6 \mu \mathrm{m}$, EHC Japan.

$\mathrm{X}$-ray diffraction patterns were recorded with a $2 \mathrm{D}$ detector (Vantec 500, Bruker). Ni filtered and pin hole collimated $\mathrm{CuK}_{\alpha}$ radiation was used. The exposure time was $30 \mathrm{~min}$ and the sample to detector distance was $8.95 \mathrm{~cm}$ and $26.7 \mathrm{~cm}$ for wide and small angle XRD experiments, respectively. Uniform orientation was achieved by alignment at the air-sample interface on top of a small droplet. The samples were held on a temperature-controlled heating stage.

The dielectric spectra $\left(\varepsilon_{\perp}^{\prime}, \varepsilon_{\perp}^{\prime \prime}\right)$ were measured on home-made planar aligned cells of cell thickness $10 \mu \mathrm{m}$ with Nissan Chemicals RN1175 alignment layer and antiparallel rubbing in a frequency range between $1 \mathrm{~Hz}$ and $10 \mathrm{MHz}$ using Novocontrol 
alpha dielectric analyser. The sample was cooled at a rate of $0.1 \mathrm{~K} \mathrm{~min}^{-1}$ from the isotropic phase and measured in the temperature range in between $193{ }^{\circ} \mathrm{C}$ and $50{ }^{\circ} \mathrm{C}$. In order of the increasing frequency of their appearance we refer to these relaxations as $\mathrm{P} 1, \mathrm{P} 2$ and $\mathrm{P} 3$, and analyse the measured $\varepsilon_{\perp}^{\prime}$ and $\varepsilon_{\perp}^{\prime \prime}$ spectra as a sum of these relaxations and the contribution from $\sigma_{\mathrm{dc}}$ to $\varepsilon_{\perp}^{\prime \prime}$, by using the relation for the complex permittivity, ${ }^{15}$

$$
\varepsilon_{\perp}^{*}(\omega)=\varepsilon_{\perp}^{\prime}-j \varepsilon_{\perp}^{\prime \prime}=\varepsilon_{\infty}+\sum_{P_{i=1}}^{i=3} \frac{\Delta \varepsilon_{i}}{\left(1+\left(j \omega \tau_{\mathrm{HN} i}\right)^{\alpha_{i}}\right)^{\beta_{i}}}-\frac{j \sigma_{\mathrm{dc}}}{\varepsilon_{0} \omega}
$$

where $\omega=2 \pi f$ is the angular frequency and $\varepsilon_{0}$ is the permittivity of free space. The subscript $i$ denotes the $i^{\text {th }}$ relaxation process. $\Delta \varepsilon_{i}=\varepsilon_{\mathrm{s} i}-\varepsilon_{\infty i}$ is the dielectric relaxation strength of this process, $\tau_{\mathrm{HN} i}$ is the Havriliak-Negami dielectric relaxation time for the $i^{\text {th }}$ process ( $i=1$ to 3 ); $\alpha_{i}$ and $\beta_{i}$ are respectively the symmetric and asymmetric broadening parameters also for the $i^{\text {th }}$ process. The term $\frac{-j \sigma_{\mathrm{dc}}}{\varepsilon_{0} \omega}$ takes account of the $\sigma_{\mathrm{dc}}$ contribution to $\varepsilon^{\prime \prime}$, and $\varepsilon_{\infty}$ is the sum of the permittivity contributions from vibrational, ionic and electronic polarisations. The imaginary part of eqn (1) is fitted to the loss spectra using the WinFit dielectric fitting program purchased from Novocontrol. For the collective mode designated here $P_{2}, \alpha_{2}$ is varied from 1.0 to 0.94 and $\beta_{2}$ is fixed at 1.0 .

\section{Results and discussion}

\subsection{DSC investigations}

The mesophases and transition temperatures of compound 1/14 are given in Scheme 1. Fig. 1 shows the DSC heating and
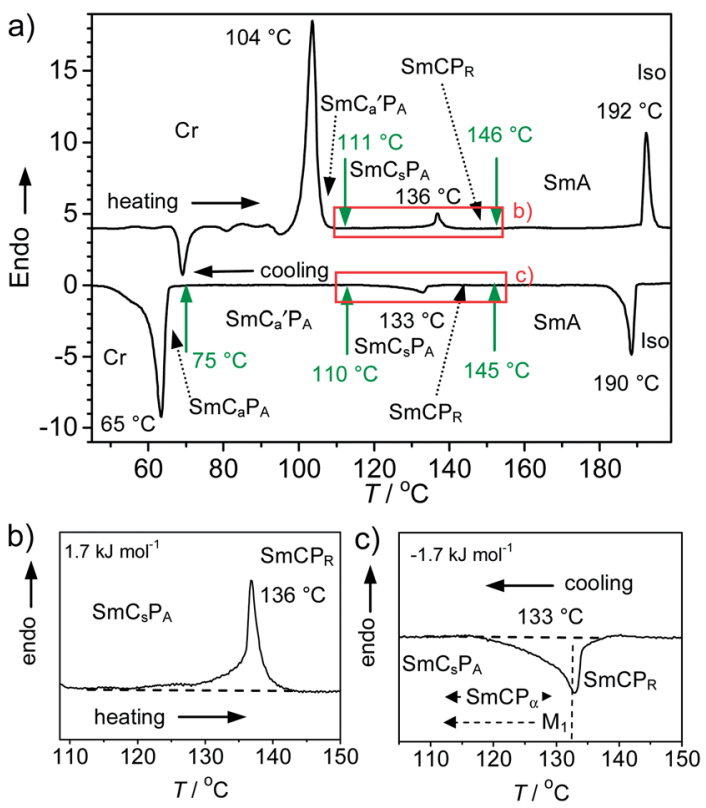

Fig. 1 (a) DSC heating and cooling curves $\left(10 \mathrm{~K} \mathrm{~min}^{-1}\right)$ of compound 1/14; continuous phase transitions are indicated in green; ( $b$ and $c$ ) show expanded temperature ranges of the $\operatorname{SmCP}_{\mathrm{P}}-\left(\mathrm{M}_{1}-\mathrm{SmCP}_{\alpha}\right)-$ $\mathrm{SmC}_{\mathrm{S}} \mathrm{P}_{\mathrm{A}}$ transition on heating and cooling, respectively $\left(T /{ }^{\circ} \mathrm{C}\right)$. cooling scans. In the DSC scans three distinct peaks in the heating and cooling curves can be assigned to first order phase transitions (Fig. 1a), a sharp transition with relatively high enthalpy $\left(\Delta H=9.7 \mathrm{~kJ} \mathrm{~mol}^{-1}\right)$ for the transition between the isotropic liquid and the liquid crystalline state occurring around $192{ }^{\circ} \mathrm{C}$ on heating and $190{ }^{\circ} \mathrm{C}$ on cooling, a phase transition with much lower enthalpy $\left(\Delta H=1.7 \mathrm{~kJ} \mathrm{~mol}^{-1}\right)$ taking place at $136{ }^{\circ} \mathrm{C}$ on heating and at $133{ }^{\circ} \mathrm{C}$ on cooling in the LC range and the melting/crystallization occurring at $T=104{ }^{\circ} \mathrm{C}$ and $T=65{ }^{\circ} \mathrm{C}$, respectively (all transitions at rates of $10 \mathrm{~K}$ $\min ^{-1}$ ). The phase transition at $136 / 133{ }^{\circ} \mathrm{C}$ with relatively low enthalpy shows a significant tailing over a temperature range of about $20 \mathrm{~K}$, especially in the cooling runs (Fig. 1b and c).

Besides these first order phase transitions there are additional continuous transitions taking place in the LC range without distinct DSC peaks (Fig. 1a), but recognized by changes of the textures, switching behaviour and dielectric response. These transitions occur at $T=145^{\circ} \mathrm{C}$ between a uniaxial and a biaxial smectic phase and additional continuous transitions take place at $T=110{ }^{\circ} \mathrm{C}$ and $75{ }^{\circ} \mathrm{C}$ on further cooling. In addition, different phases coexist in the range of the tailing $(T=$ 133-115 ${ }^{\circ} \mathrm{C}$ ) of the transition at $T=133^{\circ} \mathrm{C}$.

\subsection{Optical investigations}

In planar cells a fan-like texture, as typical for smectic phases is observed on cooling the isotropic liquid to $190{ }^{\circ} \mathrm{C}$. In the fan texture the dark extinction crosses are parallel to the directions of polarizer and analyzer, indicating the absence of a uniform tilt in this smectic phase (SmA) (Fig. 2a). The birefringence increases on cooling, especially in the temperature range between 190 and $160{ }^{\circ} \mathrm{C}$ (see Fig. S2a-d $\dagger$ ).

In homeotropically aligned samples, the SmA phase exhibits a uniform dark texture with some typical oily streak defects and Maltese crosses (Fig. 2b). At $145{ }^{\circ} \mathrm{C}$ a weakly birefringent schlieren texture develops in the dark homeotropic aligned samples, as shown in Fig. 2c, indicating a transition to an optical biaxial smectic phase (assigned as $\mathrm{SmCP}_{\mathrm{R}}$ ). This transition is not associated with any enthalpy change in the DSC traces. On further cooling the birefringence nearly disappears with a minimum around $130-132{ }^{\circ} \mathrm{C}$ (Fig. 2e) and then increases again (Fig. 2g). This minimum, occurring slightly below the maximum of the DSC peak of the $\operatorname{SmCP}_{\mathrm{R}}-\mathrm{SmC}_{\mathrm{S}} \mathrm{P}_{\mathrm{A}}$ transition, but still located in the range of the tailing of this transition (Fig. 1b and c), is associated with an inversion in the sign of the birefringence. This is confirmed by investigation with a $\lambda$-retarder plate, where the positions of the blue shifted and yellow shifted areas exchange their positions at this temperature (compare Fig. $2 \mathrm{~d}$ and $\mathrm{h}$ ), indicating a change of the major direction of the intramolecular $\pi$-conjugation pathway at that temperature.

Remarkably, however, the birefringence never goes through zero at the inversion point (Fig. 2e) which might be due to a thin birefringent surface layer formed by a surface stabilized birefringent phase $\left(\mathrm{M}_{1}\right.$, see below) coexisting with the $\mathrm{SmC}_{\mathrm{S}} \mathrm{P}_{\mathrm{A}}$ phase in this temperature region. Indeed, in the temperature range of the $\mathrm{SmC}_{\mathrm{S}} \mathrm{P}_{\mathrm{A}}$ phase between 133 and $115{ }^{\circ} \mathrm{C}$, 

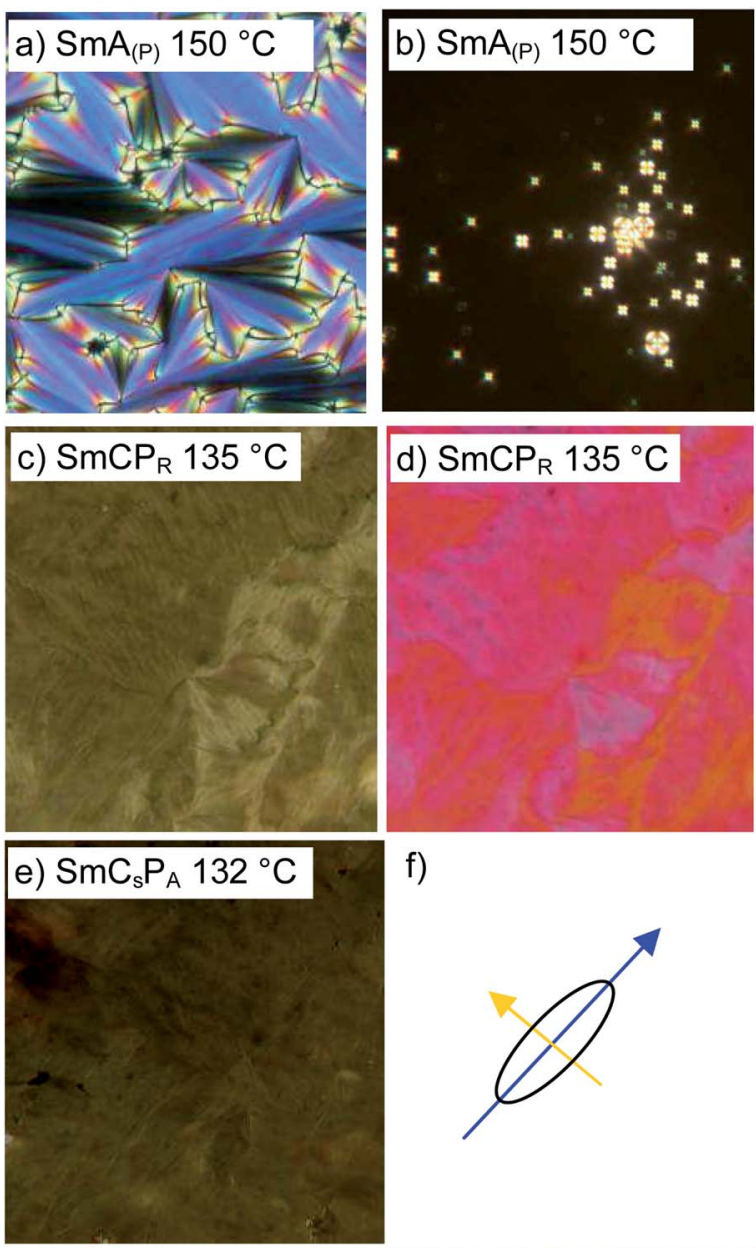

f)
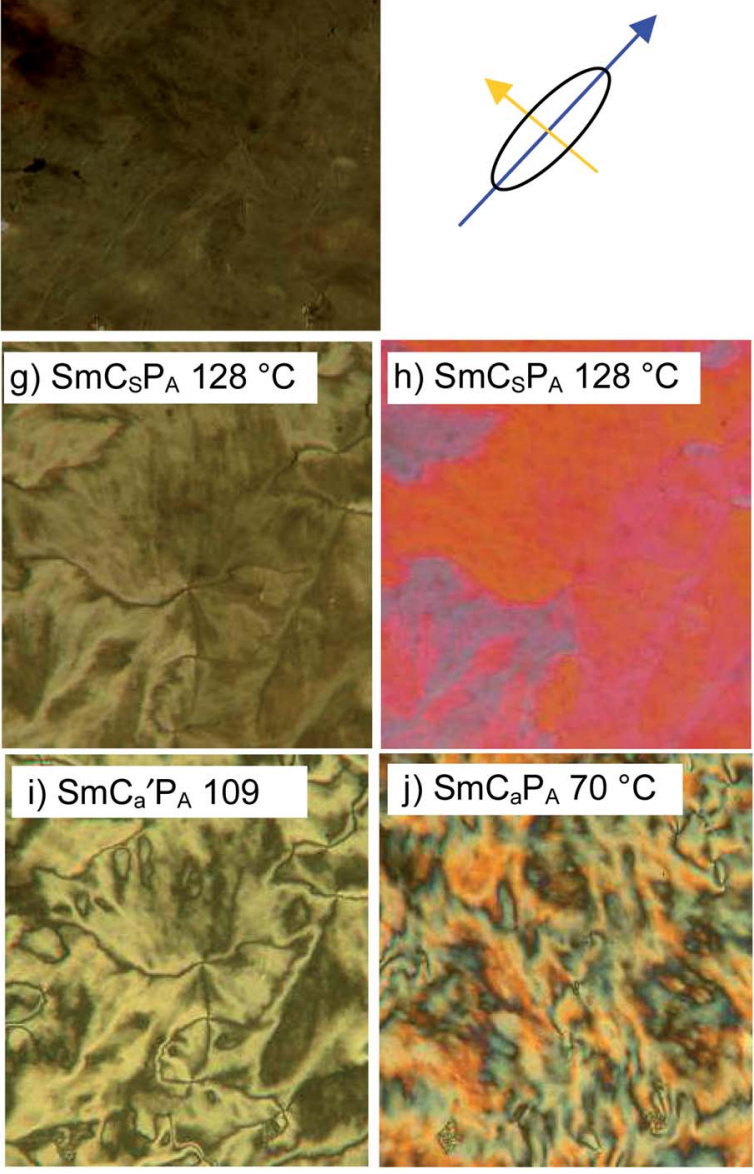

Fig. 2 Optical photomicrographs showing the textures of compound $1 / 14$ between crossed polarizers: (a) $\mathrm{SmA}_{(P)}$ phase at $T=150{ }^{\circ} \mathrm{C}$ with planar alignment; (b) same phase after shearing, leading to predominately homeotropic alignment; (c)-(e) and (g)-(j) were obtained with homeotropically aligned samples; (c) $\mathrm{SmCP}_{\mathrm{R}}$ phase as observed at $T=$ $135{ }^{\circ} \mathrm{C}$; (d) same region with additional $\lambda$-plate; (e) $\mathrm{SmC}_{\mathrm{s}} \mathrm{P}_{\mathrm{A}}$ phase at $T$ $=132{ }^{\circ} \mathrm{C}$, (f) shows the orientation of the indicatrix of the $\lambda$-retarder corresponding to the tailing in the DSC traces of the phase transition at $T=133{ }^{\circ} \mathrm{C}$ on cooling (Fig. 1c), there is a coexistence and competition of the evolving $\mathrm{SmC}_{\mathrm{S}} \mathrm{P}_{\mathrm{A}}$ phase with two other phase structures ( $\mathrm{M}_{1}$ and $\mathrm{SmCP}_{\alpha}$, see Scheme 1).

The phase assigned as $\mathbf{M}_{1}$ can most clearly be observed under strong homeotropic alignment conditions as achieved by pretreatment of the glass substrates with AL60702 (JSR, Korea, obtained through Samsung Co. Korea). Upon cooling, in these strongly homeotropic aligning cells, a highly viscous and birefringent phase with a mosaic-like texture $\left(\mathrm{M}_{1}\right)$ appears at $T=$ $133{ }^{\circ} \mathrm{C}$ (Fig. 3a). At $130-131{ }^{\circ} \mathrm{C}$ completely dark areas slowly appear and partly replace this birefringent phase (Fig. 3b). The formation of these dark areas $\left(\mathrm{SmCP}_{\alpha}\right)$ can be triggered by application of an in-plane field, but it is never complete and both phases $\mathrm{M}_{1}$ and $\mathrm{SmCP}_{\alpha}$ always coexist and replace the $\mathrm{SmC}_{\mathrm{s}} \mathrm{P}_{\mathrm{A}}$ phase under these conditions. In contrast to the birefringent $\mathrm{M}_{1}$ phase the $\mathrm{SmCP}_{\alpha}$ phase is fluid and behaves like a homeotropic aligned uniaxial smectic phase, i.e. the optically isotropic texture is retained on shearing and defect lines similar to oily streaks are formed. Hence, this phase is optical uniaxial with a high tendency for homeotropic alignment. It should be pointed out that the optical uniaxial texture of the $\mathrm{SmCP}_{\alpha}$ phase is not related to the inversion of birefringence taking place in a small range of temperature $\left(T=130-132^{\circ} \mathrm{C}\right)$ in the homeotropic aligned $\mathrm{SmC}_{\mathrm{s}} \mathrm{P}_{\mathrm{A}}$ phase. Upon further cooling there is a slow transformation of the $\mathrm{M}_{1}$ phase to the schlieren texture of the $\mathrm{SmC}_{\mathrm{s}} \mathrm{P}_{\mathrm{A}}$ phase (Fig. $2 \mathrm{~g}$ ), taking place in the temperature range between 125 and $115{ }^{\circ} \mathrm{C}$.

On slow cooling the homeotropic sample between ordinary microscopy glass plates without alignment layer (weak anchoring conditions) the optical uniaxial phase can be formed instead of the $\mathrm{SmC}_{\mathrm{S}} \mathrm{P}_{\mathrm{A}}$ phase at $\sim 133{ }^{\circ} \mathrm{C}$. Once formed, it completely replaces the $\mathrm{SmC}_{\mathrm{S}} \mathrm{P}_{\mathrm{A}}$ phase, in this case without a coexisting $\mathrm{M}_{1}$ phase. The $\mathrm{SmCP}_{\alpha}$ phase is retained down to $T=$ $\sim 115{ }^{\circ} \mathrm{C}$ when it transforms to the $\mathrm{SmC}_{\mathrm{s}} \mathrm{P}_{\mathrm{A}}$ phase. On re-heating with medium rates of temperature $\left(5-10 \mathrm{~K} \mathrm{~min}^{-1}\right)$ the $\mathrm{SmC}_{\mathrm{S}} \mathrm{P}_{\mathrm{A}}$ phase is retained up to the phase transition to the $\mathrm{SmCP}_{\mathrm{R}}$ phase at $136{ }^{\circ} \mathrm{C}$ without formation of $\mathrm{SmCP}_{\alpha}$. However, by using slower heating rates the optical isotropic $\mathrm{SmCP}_{\alpha}$ phase can develop at $T \geq 125^{\circ} \mathrm{C}$ on heating, too. So the phase behavior in this temperature range is very complex, associated with strong hysteresis effects, phase coexistence regions, and furthermore, being very sensitive to slight changes in experimental conditions and the sample history (see Scheme 1). In planar cells the $\mathrm{SmCP}_{\alpha}$ and $\mathrm{SmC}_{\mathrm{s}} \mathrm{P}_{\mathrm{A}}$ phases appear with fan-textures, having their extinction crosses either parallel or slightly inclined to the directions of the polarizers, respectively (see Fig. 6e and Fig. S2e-j $\dagger$ ). The $M_{1}$ phase could not be clearly identified. Due to this condition-dependent coexistence of different structures the investigations of the phases in the temperature range between

plate; (g) $\mathrm{SmC}_{\mathrm{S}} \mathrm{P}_{\mathrm{A}}$ phase at $T=128{ }^{\circ} \mathrm{C}$ after inversion of birefringence, (h) same region with additional $\lambda$-plate; the exchange of bluish/orange areas indicates the inversion of birefringence; see also Fig. $\mathrm{S} 3 \dagger$ for enlarged images of (c), (d) and (g), (h); (i) $\mathrm{SmC}_{a}^{\prime} \mathrm{P}_{\mathrm{A}}$ phase at $T=109^{\circ} \mathrm{C}$ and (j) $\mathrm{SmC}_{\mathrm{a}} \mathrm{P}_{\mathrm{A}}$ phase at $T=70^{\circ} \mathrm{C}$; photos (c)-(e) and (g) $-(\mathrm{j})$ show the same region. 

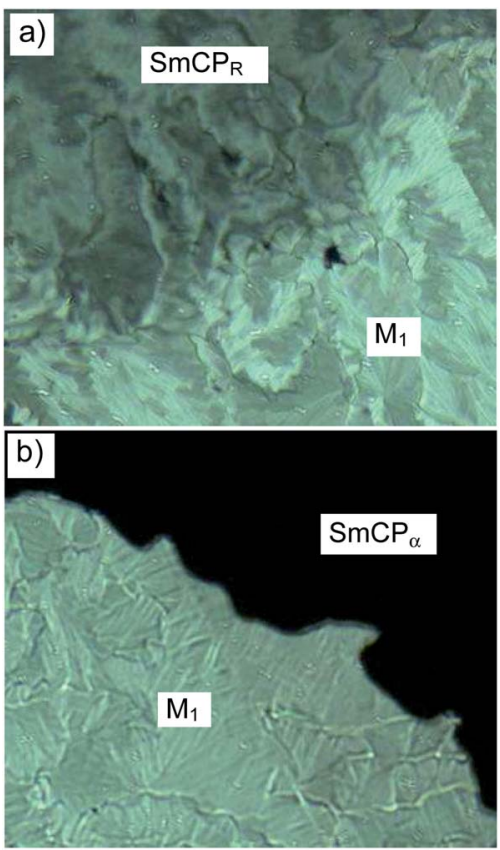

Fig. 3 (a) $S m C P_{R}$ to $M_{1}$ transition at $T=133{ }^{\circ} \mathrm{C}$ and (b) $M_{1}$ to $S m C P_{\alpha}$ transition at $T=130.5^{\circ} \mathrm{C}$ as observed on cooling in a homeotropic $8 \mu \mathrm{m}$ cell.

115 and $133{ }^{\circ} \mathrm{C}$ and the proper interpretation of the results are difficult. ${ }^{16}$ Nevertheless, combined results from the different methods, together with the analysis of the development of the distinct structures depending on temperature allows us to discuss some general conclusions (see Sections 3.7.8 and 4).

On further cooling the birefringence of the schlieren texture of the $\mathrm{SmC}_{\mathrm{S}} \mathrm{P}_{\mathrm{A}}$ increases, associated with distinct textural changes at $\sim 110{ }^{\circ} \mathrm{C}$ (transition to $\mathrm{SmC}_{\mathrm{a}}^{\prime} \mathrm{P}_{\mathrm{A}}$ ) and $\sim 75^{\circ} \mathrm{C}$ at the transition to the $\operatorname{SmC}_{\mathrm{a}} \mathrm{P}_{\mathrm{A}}$ phase (see Fig. $2 \mathrm{i}$ and $\mathrm{j}$ ). These transitions are continuous and not associated with any change in enthalpy (see Fig. 1).

\subsection{Polarization current curves}

Switching experiments under a triangular wave voltage were carried out in $6 \mu \mathrm{m}$ coated ITO cells under an applied triangular wave AC voltage with a frequency of $10 \mathrm{~Hz}$ and under a peak to peak voltage of $160 \mathrm{~V}$, corresponding to $\pm 26.7 \mathrm{~V} \mathrm{\mu m}^{-1}$. There is no polarization current peak in the isotropic liquid at $T=$ $196{ }^{\circ} \mathrm{C}$ (Fig. 4a) and a single peak in each half period of the applied field emerges shortly below the phase transition from the isotropic liquid at approximately $184{ }^{\circ} \mathrm{C}$ in the temperature range of the uniaxial SmA phase and increases in intensity on further cooling (peak A in Fig. 4b). However, there is no recognizable field induced birefringence, as obtained in a homeotropic cell under an applied in-plane field in the whole temperature range of this phase and therefore this $\mathrm{SmA}$ phase is considered as paraelectric $\operatorname{SmA}$ phase $\left(\operatorname{SmA}_{(\mathrm{P})}\right)$.

In the $\mathrm{SmA}_{(\mathrm{P})}$ range the polarization peak is slightly shifted to lower voltage, becomes relatively sharp by further decreasing the temperature (Fig. 4c) and reaches a value of $150 \mathrm{nC} \mathrm{cm}^{-2}$
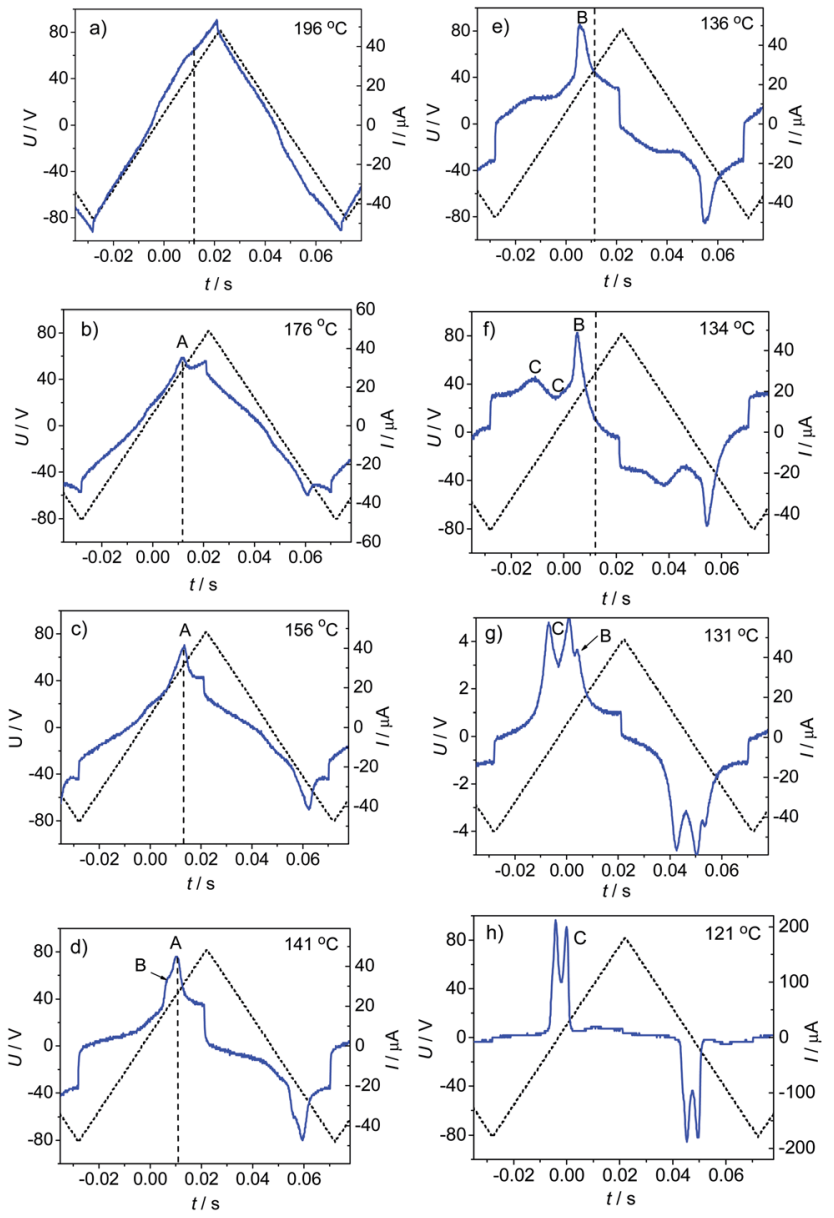

Fig. 4 Switching current response curves of compound 1/14 recorded by applying a triangular wave voltage $\left(160 \mathrm{~V}_{\mathrm{pp}}, 10 \mathrm{~Hz}, 5 \mathrm{k} \Omega\right)$ to a $6 \mu \mathrm{m}$ coated ITO cell with planar alignment layer at the indicated temperatures in the distinct phases: (a) isotropic liquid phase; (b) and (c) $\mathrm{SmA}_{(P)}$ phase region, (d) and (e) $S m C P_{R}$ phase; (f) $S m C P_{R}-S m C_{S} P_{A}$ transition; (g) and (h) $\mathrm{SmC}_{S} \mathrm{P}_{\mathrm{A}}$ phase; for additional polarization current curves in the $\mathrm{SmC}_{\mathrm{a}}^{\prime} \mathrm{P}_{\mathrm{A}}$ and $\mathrm{SmC}_{\mathrm{a}} \mathrm{P}_{\mathrm{A}}$ phases, see Fig. S5. $\dagger$

before the transition to the next phase (Fig. 5). At $145^{\circ} \mathrm{C}$, at the transition to the $\mathrm{SmCP}_{\mathrm{R}}$ phase, a second polarization peak (B) emerges which grows and at first coexists with the peak $\mathrm{A}$, which

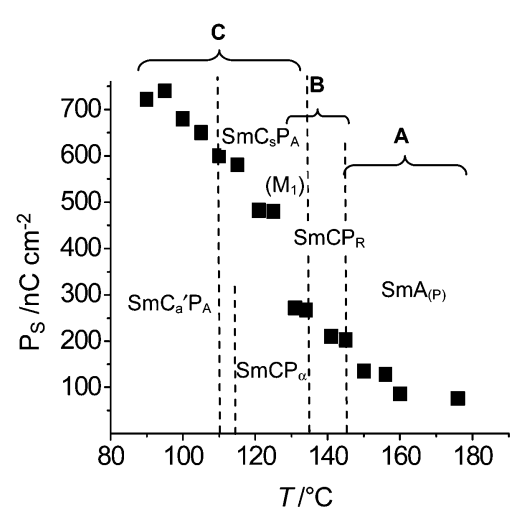

Fig. 5 Polarization values of compound 1/14 depending on temperature and phase type; $(A-C)$ refer to the current peaks shown in Fig. 4 , also indicating overlapping ranges. 
continuously decreases in intensity (Fig. 4d). Peak B completely replaces peak A at $T=136{ }^{\circ} \mathrm{C}$ (Fig. 4e). This peak B appears at a lower voltage and is sharper than peak $A$ in the $\operatorname{SmA}_{(\mathrm{P})}$ phase, indicating a significantly increased size of the polar domains, which retain a ferroelectric correlation in the domains; the polarization values increase further to $270 \mathrm{nC} \mathrm{cm}^{-2}$ in the $\mathrm{SmCP}_{\mathrm{R}}$ phase before the transition to the next phases $\left(\mathrm{SmCP}_{\alpha}\right.$ and $\mathrm{SmC}_{\mathrm{S}} \mathrm{P}_{\mathrm{A}}$ ) takes place (Fig. 5). ${ }^{17}$

At $T=135{ }^{\circ} \mathrm{C}$ two diffuse peaks start developing (C), one at lower voltage and a second one overlapping with the single peak B (Fig. 4f). With decreasing temperature these two peaks rapidly become sharper, increase in size (Fig. 4g) and replace the single peak $\mathrm{B}$. In the temperature range between $133{ }^{\circ} \mathrm{C}$ and $129{ }^{\circ} \mathrm{C}$ peaks B and C still coexist and at $T=129^{\circ} \mathrm{C}$ peak B has nearly completely disappeared. Below this temperature the two polarization peaks become sharper, come closer together and further increase in size (Fig. 4h), reaching polarization values between 600 and $760 \mathrm{nC} \mathrm{cm}^{-2}$ in this $\operatorname{SmC}_{\mathrm{a}}^{\prime} \mathrm{P}_{\mathrm{A}}$ phase region (Fig. 5). On further cooling, in the $\mathrm{SmC}_{\mathrm{a}} \mathrm{P}_{\mathrm{A}}$ range, the polarization does not change, but the peaks merge to only one, possibly due to the increased viscosity (Fig. S5b $\dagger$ ). The increased viscosity is in line with dielectric investigations, see Section 3.5 and Fig. S6 and S7†.

\subsection{Planar textures and electrooptical investigations}

Fig. 6 shows a comparison of textures of planar cells before (left side) and after applying an electric field (right side). Without applied field the extinction crosses in the $\operatorname{SmA} / \operatorname{SmA}_{(\mathrm{P})}$ phase region coincide with the directions of the polarizers (Fig. 6a), confirming non-tilted phases. There is no change if an electric field is applied (Fig. 6b). Also in the region between 145 and $133{ }^{\circ} \mathrm{C}$, assigned as $\mathrm{SmCP}_{\mathrm{R}}$, the extinction crosses are still parallel to polarizer and analyzer, though a nonspecific grainy texture develops under the applied field over the whole texture (see Fig. 6c and d). This grainy texture is strongly fluctuating and appears to be the result of electro-convections or fluctuations of biaxial/polar domains in the $\operatorname{SmCP}_{\mathrm{R}}$ phase. Below $133{ }^{\circ} \mathrm{C}$, in the $\mathrm{SmC}_{\mathrm{S}} \mathrm{P}_{\mathrm{A}}$ phase range, this feature disappears and the extinction crosses become inclined with respect to the polarizers by an angle of about $10^{\circ}$ (Fig. 6e). Under the field the tilt is retained, only the birefringence is slightly increased, indicating a switching around the long axis (Fig. 6f), which might be favoured by the relatively small tilt of the molecules in this temperature range. In the case that the $\operatorname{SmCP}_{\alpha}$ phase is formed, the extinction crosses remain parallel to the polarizers and switching takes place by rotation on a cone, leading to synclinic field induced $\mathrm{SmC}_{\mathrm{S}} \mathrm{P}_{\mathrm{F}}$ states. (see Fig. $\mathrm{S} 2 \mathrm{~h}-\mathrm{j} \dagger$ ).

A major change is observed at $\sim 110{ }^{\circ} \mathrm{C}$ when the birefringence of the sample at $0 \mathrm{~V}$ drops significantly as indicated by the birefringence colour change from purple/blue to red (Fig. 6e and $\mathrm{g}$ ). This is associated with a change of the position of the extinctions from being inclined with the polarizers to parallel to the polarizers in the $\mathrm{SmC}_{\mathrm{S}} \mathrm{P}_{\mathrm{A}}$ phase, indicating a transition from synclinic to anticlinic tilt correlation $\left(\mathrm{SmC}_{\mathrm{S}} \mathrm{P}_{\mathrm{A}}-\mathrm{SmC}_{\mathrm{a}}^{\prime} \mathrm{P}_{\mathrm{A}}\right.$ transition). Under an applied field the extinctions become inclined again (Fig. 6h) and the birefringence is considerably enhanced
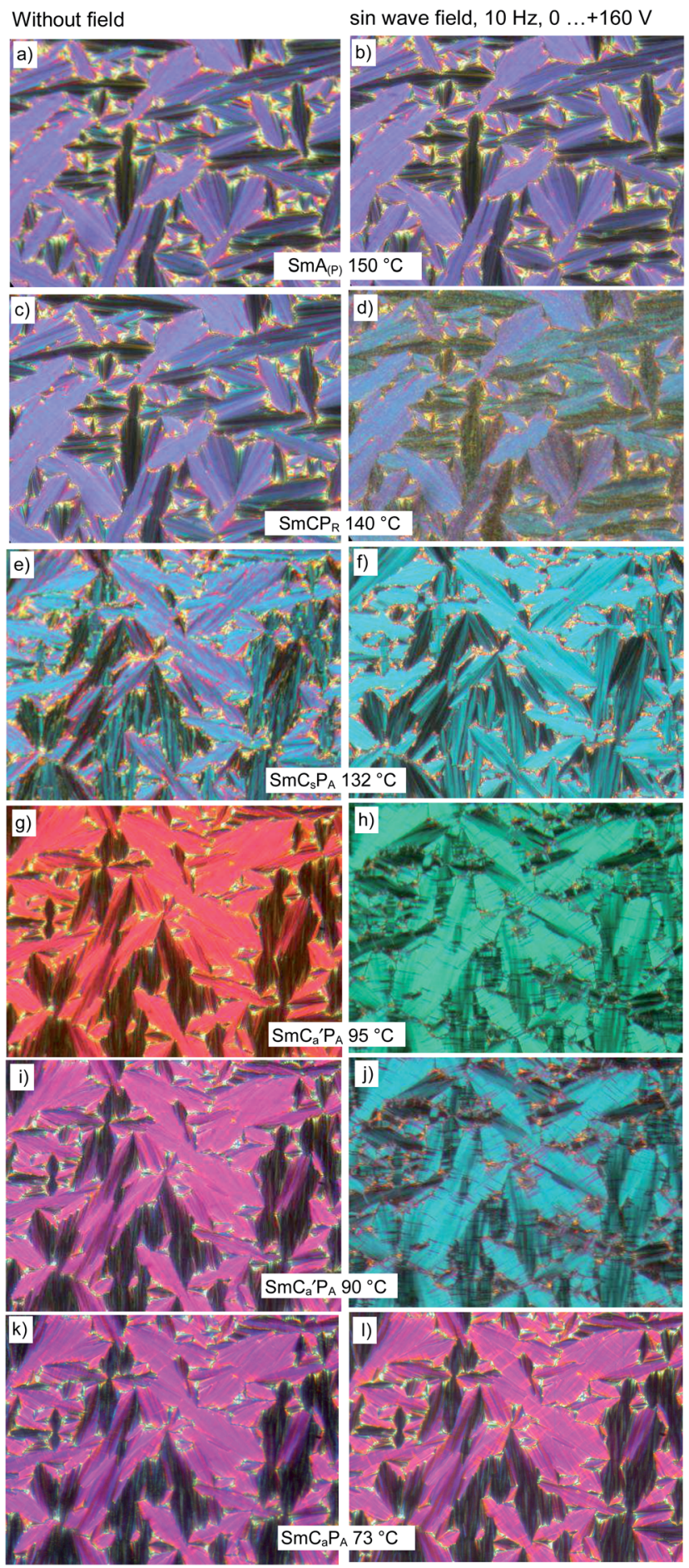

Fig. 6 Textures of compound 1/14 as observed in PI-coated ITO-cells $(6 \mu \mathrm{m})$ under an electric field (sinusoidal wave field, $f=10 \mathrm{~Hz}$, alternating between 0 and $+160 \mathrm{~V}$, right column) and after switching off the applied field at $0 \mathrm{~V}$ (left column) in the distinct phases at the indicated temperatures; additional textures are shown in Fig. $\mathrm{S} 2 \uparrow$.

(red to green), which can be explained by a switching process taking place by rotation on a cone, giving rise to a field induced anticlinic to synclinic transition. ${ }^{18}$ Probably, the denser packing in the $\mathrm{SmC}_{\mathrm{a}}^{\prime} \mathrm{P}_{\mathrm{A}}$ phase favours this mode of switching though the tilt is still small. 
Within the temperature range of the $\mathrm{SmC}_{\mathrm{a}}^{\prime} \mathrm{P}_{\mathrm{A}}$ phase the birefringence of the $0 \mathrm{~V}$ textures rises with decreasing temperature (colour change from red to pink, see Fig. $6 \mathrm{~g}$ and i) due to denser packing and increased polar order of the molecules (increase of polarization values, $P_{\mathrm{s}}$, see Fig. 5). Also under the applied field the extinction crosses retain a position coinciding with the polarizers (Fig. 6j). However, in the field induced states the birefringence decreases more strongly with decreasing temperature (color change from green to blue), and the extinction crosses align more and more parallel to the polarizers (Fig. $6 \mathrm{~h}$ and j). This can be explained by a change of the switching process from a rotation on a cone, preferentially occurring at higher temperature (field induced $\mathrm{SmC}_{\mathrm{a}}^{\prime} \mathrm{P}_{\mathrm{A}}$ to $\mathrm{SmC}_{\mathrm{S}} \mathrm{P}_{\mathrm{F}}$ transition) and inducing a synclinic tilt, to a collective rotation around the long axis at lower temperature, (field induced $\mathrm{SmC}_{\mathrm{a}}^{\prime} \mathrm{P}_{\mathrm{A}}$ to $\mathrm{SmC}_{\mathrm{a}}^{\prime} \mathrm{P}_{\mathrm{F}}$ transition) retaining the anticlinic tilt. This change in switching mechanism is most likely due to the increase in viscosity of the sample. ${ }^{19}$ The coexistence of two distinct switching mechanisms not only explains the change of the direction of the extinctions in the field induced textures depending on temperature, it could also be the reason for the splitting of the polarization peaks occurring in the low temperature range of the $\mathrm{SmC}_{\mathrm{a}}^{\prime} \mathrm{P}_{\mathrm{A}}$ phase region (Fig. S5a $\dagger$ ).

Below $75{ }^{\circ} \mathrm{C}$, in the range of the $\mathrm{SmC}_{\mathrm{a}} \mathrm{P}_{\mathrm{A}}$ phase, the switching seems to take place exclusively around the long axis which leads to nearly identical birefringence and unchanged orientation of the extinctions for the states with and without field (Fig. 6k and 1). This is mainly attributed to the increased viscosity in this temperature range.

\subsection{Dielectric investigations}

Dielectric spectroscopy was performed in a planar cell of $10 \mu \mathrm{m}$ thickness in a frequency range between $1 \mathrm{~Hz}$ and $10 \mathrm{MHz}$ on cooling from the isotropic phase and at temperatures in between $193{ }^{\circ} \mathrm{C}$ and $50{ }^{\circ} \mathrm{C}$. The frequency dependence of the imaginary part of the dielectric permittivity $\left(\varepsilon_{\perp}^{\prime \prime}\right)$ for selected temperatures is shown in Fig. 7a. (A complete set of the same data is given in Fig. S6. $\dagger$ ) Three relaxation processes, P1, P2 and $\mathrm{P} 3$ were observed in the measured frequency range. The low frequency process P1 is attributed to conductivity and the high frequency relaxation process $\mathrm{P} 3$ can be observed in the frequency window only below $100{ }^{\circ} \mathrm{C}$ and this is assigned to rotation around the short axis, its frequency decreases and the relaxation strength increases with a reduction in temperature; the relaxation frequency follows $2 S+1$ dependence, $S$ being the orientational order parameter. The dielectric strength $\delta \varepsilon_{3}$ and the relaxation frequency $f_{\mathrm{R}, 3}$ of $\mathrm{P} 3$ are given in Fig. S7. $\dagger \mathrm{P} 2$ (the medium frequency relaxation process) appears in the measured frequency range below $\sim 186{ }^{\circ} \mathrm{C}$ and exists down to $50{ }^{\circ} \mathrm{C}$. The peak is assigned to the polar switching mechanism. The dielectric strength $\left(\delta \varepsilon_{2}\right)$ and the relaxation frequency $\left(f_{\mathrm{R}, 2}\right)$ of $\mathrm{P} 2$ were obtained by fitting the relaxation spectra to the HavriliakNegami equation. ${ }^{15}$

Fig. 7b shows the temperature dependence of $\delta \varepsilon_{2}$ and $f_{\mathrm{R}, 2}$ for the process $\mathrm{P} 2 . f_{\mathrm{R}, 2}$ decreases with decreasing temperature with small steps at $146{ }^{\circ} \mathrm{C}$ and around $130{ }^{\circ} \mathrm{C}$. $\delta \varepsilon_{2}$ increases and
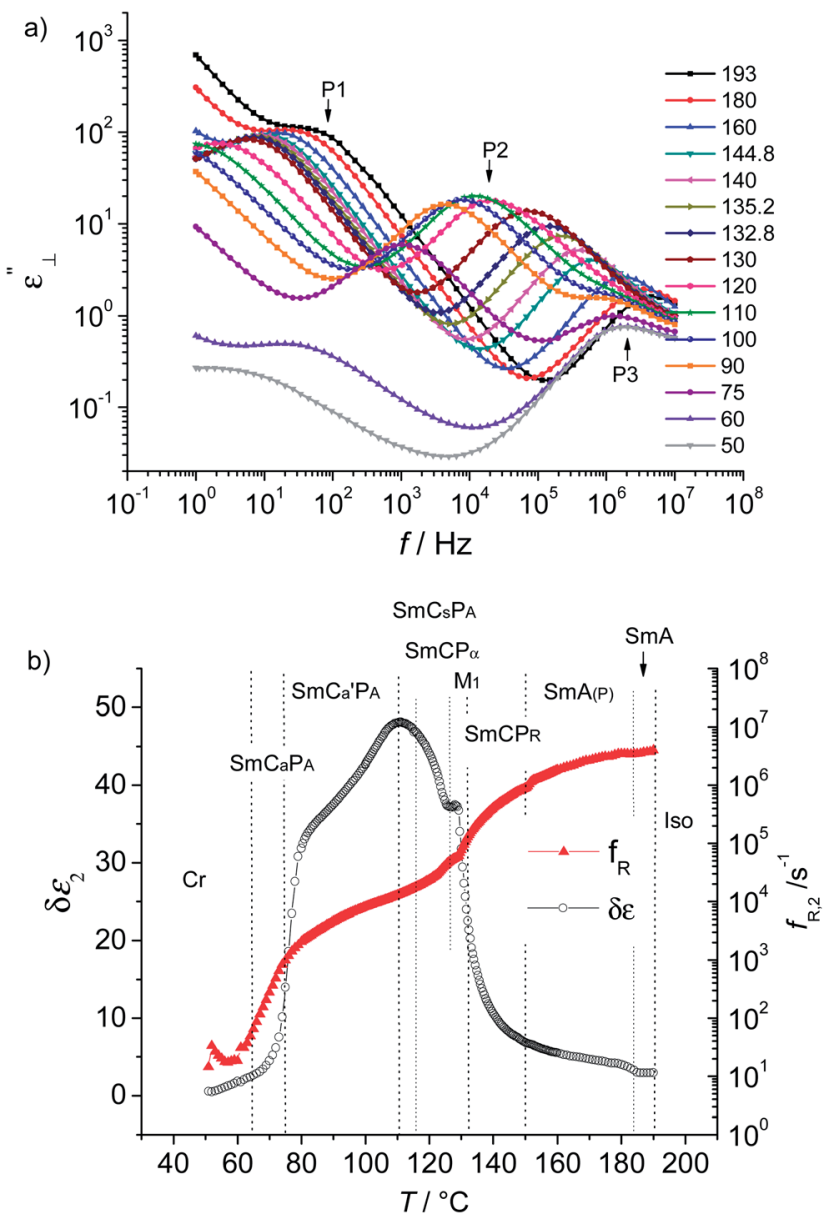

Fig. 7 Dielectric investigation of compound 1/14: (a) temperature dependence of $\varepsilon_{\perp}^{\prime \prime}$ on temperature as observed in a $10 \mu \mathrm{m}$ planar cell in the frequency range from 1 to $10^{6} \mathrm{~Hz}$ in the temperature range between 193 and $50{ }^{\circ} \mathrm{C}$ (selected curves, for the full data set, see Fig. $\mathrm{S} 6 \dagger$ ); (b) temperature dependence of the dielectric strength $\left(\delta \varepsilon_{2}\right)$ and the relaxation frequency $\left(f_{\mathrm{R}, 2}\right)$ for $\mathrm{P} 2$; dielectric strength and relaxation frequency for $\mathrm{P} 3$ are given in Fig. $\mathrm{S} 7 \dagger$.

reaches a value of $\sim 7$ in the temperature range of the $\operatorname{SmA}_{(\mathrm{P})}$ phase close to the transition to $\mathrm{SmCP}_{\mathrm{R}}$. This confirms the presence of polar clusters already in the $\operatorname{SmA}_{(\mathrm{P})}$ phase. In the range of the $\mathrm{SmCP}_{\mathrm{R}}$ phase the slope of the curve becomes very steep until $\delta \varepsilon_{2}=38$ is reached at $T \sim 130{ }^{\circ} \mathrm{C}$, indicating a strong increase of the size of the polar domain. After a short plateau $\delta \varepsilon_{2}$ further rises in the temperature range of the $\mathrm{SmCP}_{\alpha}$ and $\mathrm{SmC}_{\mathrm{S}} \mathrm{P}_{\mathrm{A}}$ phases and reaches a maximum $\left(\delta \varepsilon_{2}=48\right)$ at $T=110{ }^{\circ} \mathrm{C}$, corresponding to the $\mathrm{SmC}_{\mathrm{s}} \mathrm{P}_{\mathrm{A}}-\mathrm{SmC}_{\mathrm{a}}^{\prime} \mathrm{P}_{\mathrm{A}}$ transition temperature. This indicates that even in the $\mathrm{SmC}_{\mathrm{S}} \mathrm{P}_{\mathrm{A}}$ range polar domains with limited size are present and a set of uniformly polar layers is not yet achieved. It is therefore likely that this phase consists of $\mathrm{SmC}_{\mathrm{S}} \mathrm{P}_{\mathrm{F}}$ domains with relatively large sizes. Below $T=110{ }^{\circ} \mathrm{C}$, in the $\mathrm{SmC}_{\mathrm{a}}^{\prime} \mathrm{P}_{\mathrm{A}}$ phase range, $\delta \varepsilon_{2}$ decreases, which indicates that the coherence length of the polar domains further grows. Also the polarization values increase to a range as typical for $\mathrm{B}_{2}$ phases $\left(P_{\mathrm{s}}=600-760 \mathrm{nC} \mathrm{cm}^{-2}\right.$, see Fig. 5). The steep decrease in $\delta \varepsilon_{2}$ and $f_{\mathrm{R}, 2}$ below $T=80{ }^{\circ} \mathrm{C}$ indicates that uniformly polar layers with antipolar correlation form the 
$\mathrm{SmC}_{\mathrm{a}} \mathrm{P}_{\mathrm{A}}$ phase, similar to the classical $\mathrm{B}_{2}$ phases of the usual bent-core mesogens.

A major increase in $\delta \varepsilon_{2}$, and hence, major growth in the size of the polar domains takes place in the temperature range in between $136{ }^{\circ} \mathrm{C}$ and $\sim 130{ }^{\circ} \mathrm{C}$, i.e. starting at the inflection point of the phase transition with a maximum at $133^{\circ} \mathrm{C}$ and covering a part of its tailing (Fig. 1c). In this temperature range the transition between $\mathrm{SmCP}_{\mathrm{R}}$ and $\mathrm{SmC}_{\mathrm{S}} \mathrm{P}_{\mathrm{A}}$ and the inversion of birefringence take place and the additional mesophases $\mathbf{M}_{1}$ (viscous birefringent phase) and $\mathrm{SmCP}_{\alpha}$ (optical uniaxial polar smectic phase) appear under certain conditions. The small plateau between 127 and $130{ }^{\circ} \mathrm{C}$ could possibly be due to the formation of the $\mathrm{M}_{1}$ phase, either coexisting with the $\mathrm{SmC}_{\mathrm{S}} \mathrm{P}_{\mathrm{A}}$ / $\mathrm{SmCP}_{\alpha}$ phases or replacing them in this temperature region.

\subsection{X-ray scattering}

The XRD patterns of a surface aligned sample in the temperature range between 100 and $160{ }^{\circ} \mathrm{C}$, covering all LC phases with exception of the $\mathrm{SmC}_{\mathrm{a}} \mathrm{P}_{\mathrm{A}}$ phase at lowest temperature, show a diffuse scattering in the wide angle region and only one sharp Bragg reflection in the small angle region at $d=5.1-5.3 \mathrm{~nm}$ (Fig. 8a and b). The $d$-value is a bit smaller than the molecular length $\left(L_{\mathrm{mol}}=6.0-6.6 \mathrm{~nm}\right.$ depending on the assumed molecular conformation, see Fig. S1†) confirming the presence of smectic phases in the whole investigated temperature range. Based on the $d / L_{\text {mol }}$ ratio of $\sim 0.80-0.88$ the presence of a tilt is in principle possible. There is only a very weak second order harmonics of the layer reflection indicating rather diffuse interlayer interfaces. The slight shift of the outer diffuse scattering maxima from $d=0.47 \mathrm{~nm}\left(160{ }^{\circ} \mathrm{C}\right)$ to $d=0.45 \mathrm{~nm}$ $\left(100{ }^{\circ} \mathrm{C}\right)$ indicates an increasing packing density of the molecules in the layers at reduced temperature, especially in the $\mathrm{SmC}_{\mathrm{a}}^{\prime} \mathrm{P}_{\mathrm{A}}$ phase. Nevertheless, the scattering remains completely diffuse, indicating fluid smectic phases without in-plane order in all investigated phases. The position of the small angle scattering is $90 \pm 5^{\circ}$ with respect to the maxima of the wide angle scattering. The distribution of the wide angle scattering is relatively broad for a smectic phase though there is no clear indication of a splitting or inclination of the small angle or wide angle scatterings. Hence, a tilted organization of the molecules with relatively small tilt angle, as confirmed by optical investigations (see Sections 3.3 and 3.5), would be in agreement with the XRD data, though the XRD patterns of aligned samples cannot provide any additional proof for the tilted organization.

However, the precise measurement of the $d$-value of the layer reflection depending on temperature (shown in Fig. 8c, obtained by slow cooling) indicates a temperature dependence of the $d$-value which is distinct in the different phase regions. For non-tilted smectic phases the $d$-values usually grow with decreasing temperature due to the growing packing density, associated with a stretching of the alkyl chains. This growth of the $d$-value can be observed in the $\operatorname{SmA} / \operatorname{SmA}_{(\mathrm{P})}$ and $\operatorname{SmCP}_{\mathrm{R}}$ phase regions (region a in Fig. 8c). However, this growth decreases at $\sim 133{ }^{\circ} \mathrm{C}$ and stops around $\sim 130{ }^{\circ} \mathrm{C}$ and then the $d$ values decrease in region $b$. The decrease continues down to $\sim 124{ }^{\circ} \mathrm{C}$ and indicates the onset or the substantial increase of a a)

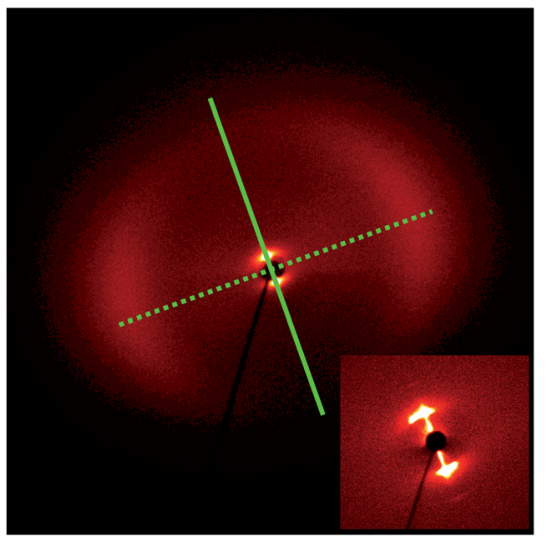

b)
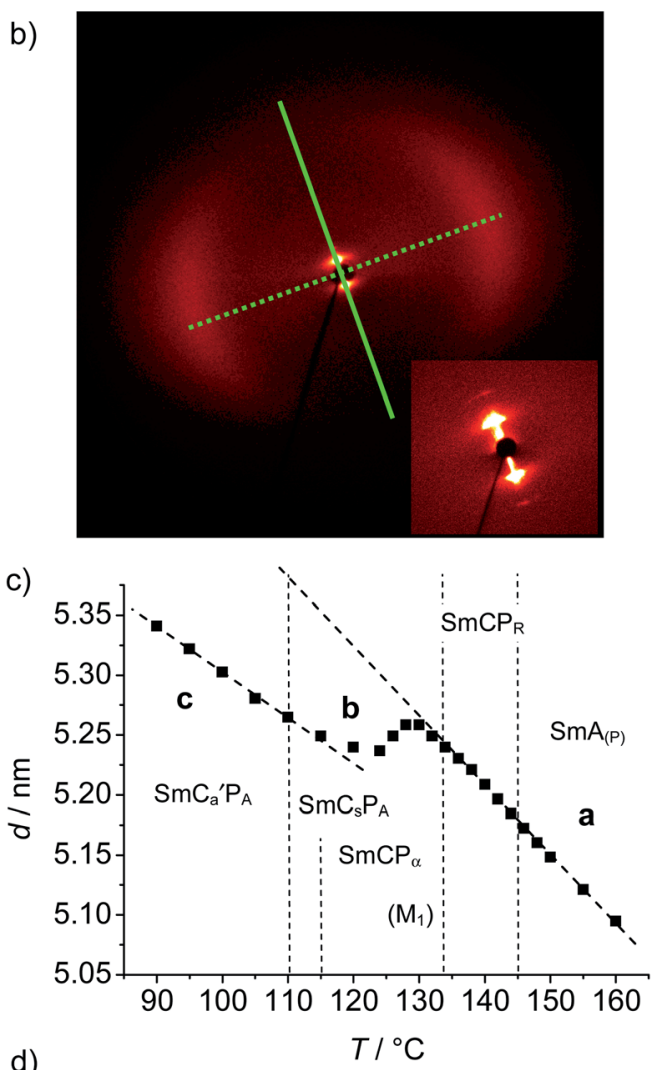

d)

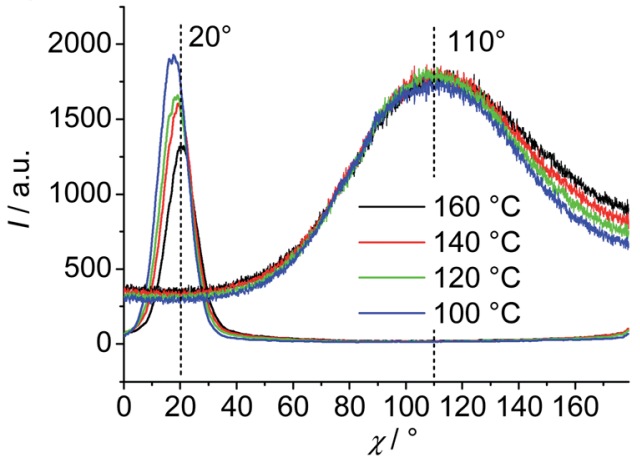

Fig. 8 XRD patterns of a surface aligned sample of compound 1/14: (a) in the $\mathrm{SmA}_{(\mathrm{P})}$ phase at $160{ }^{\circ} \mathrm{C}$; (b) in the $\mathrm{SmC}_{\mathrm{S}} \mathrm{P}_{\mathrm{A}}$ phase at $120{ }^{\circ} \mathrm{C}$; the insets show the small angle scatterings; (c) temperature dependence of the layer reflection; (d) $\chi$-scans over the wide and small angle scattering at different temperatures. 
tilt at this temperature. After the minimum around $124{ }^{\circ} \mathrm{C}$ the slope of the $d=f(T)$ curve increases again and then remains constant below $\sim 110{ }^{\circ} \mathrm{C}$ in the measured temperature range of the $\mathrm{SmC}_{\mathrm{a}}^{\prime} \mathrm{P}_{\mathrm{A}}$ phase (region $\mathrm{c}$ in Fig. $8 \mathrm{c}$ ). At the $\mathrm{SmA}_{(\mathrm{P})}-\mathrm{SmCP}_{\mathrm{R}}$ transition temperature at $T=145{ }^{\circ} \mathrm{C}$, when phase biaxiality sets in, no visible change of the slope of the $d=f(T)$ curve can be identified (see line a in Fig. 8c). If the onset of biaxiality would be only due to restricted rotation of the molecules around the long axis the increased packing density should give rise to an increase of $d=f(T)$ at this temperature. On the other hand, if biaxiality would be due to the onset of a tilt, then $d=f(T)$ should decrease. Both are not the case, and this could be explained by the onset of a small tilt, coupled with a restricted rotation of the aromatic cores in this $\mathrm{SmCP}_{\mathrm{R}}$ phase. Though this coupling of tilt and molecular biaxiality is inherent to SmC phases, the bent molecular shape leads to a significant molecular biaxiality. Hence the influence of molecular biaxiality on the properties is more pronounced than in usual SmC phases and appears to be also responsible for the observed inversion of birefringence.

In the temperature range between $\sim 133$ and $115{ }^{\circ} \mathrm{C}$ up to three mesophases could coexist $\left(\mathrm{SmC}_{\mathrm{S}} \mathrm{P}_{\mathrm{A}}, \mathrm{M}_{1}\right.$ and $\left.\mathrm{SmCP}_{\alpha}\right)$. Therefore, the scattering in this region cannot unambiguously be assigned to a specific phase structure, but the fact that no additional reflections can be identified in the XRD patterns in this temperature region suggests that the fundamental structures of these three optically very different phases should not be very different and fundamentally based on a lamellar organization.

\subsection{Discussion of the phase structures}

In this section the results from $\mathrm{XRD}$, optical, dielectric and electrooptical investigations obtained with compound 1/14 will be combined in an attempt to understand the observed sequence $\mathrm{SmA}^{-} \mathrm{SmA}_{(\mathrm{P})}-\mathrm{SmCP}_{\mathrm{R}}-\left(\mathrm{M}_{1} / \mathrm{SmCP}_{\alpha}\right)-\mathrm{SmC}_{\mathrm{S}} \mathrm{P}_{\mathrm{A}}-\mathrm{SmC}_{\mathrm{a}}^{\prime} \mathrm{P}_{\mathrm{A}}-$ $\mathrm{SmC}_{\mathrm{a}} \mathrm{P}_{\mathrm{A}}$ (see Scheme 1 and Fig. 1).

3.7.1 SmA phase. As indicated by dielectric (Fig. 7) and switching experiments (Fig. 4 and 5) only above $\sim 184{ }^{\circ} \mathrm{C}$ the SmA phase behaves as an ordinary nonpolar SmA phase, but already at $\sim 184{ }^{\circ} \mathrm{C}$ local polar order develops (Fig. $4 \mathrm{~b}$ and $\mathrm{c}$ and $7 \mathrm{~b})$ and the correlation length of the polar domain grows as the packing density of the molecules increases with decreasing temperature (see increase of the $d$-values in Fig. 8c). As under an applied in-plane field no birefringence could be induced, the coherence length of the polar domains is still relatively small and hence this region of the SmA phase between $\sim 184$ and $145{ }^{\circ} \mathrm{C}$ is assigned as paraelectric $\operatorname{SmA}\left(\operatorname{SmA}_{(\mathrm{P})}\right)$.

3.7.2 $\operatorname{SmCP}_{\mathbf{R}}$ phase. At the second order phase transition at $\sim 145{ }^{\circ} \mathrm{C}$ to the phase assigned as $\mathrm{SmCP}_{\mathrm{R}}$ the slope of the dielectric strength $\delta \varepsilon_{2}$ starts rising more steeply (Fig. 7b), a relatively sharp single peak occurs in the polarization curves (Fig. 4d and e) and optical phase biaxiality emerges (Fig. 2c). Though there is macroscopic biaxiality the polar order is still local as indicated by the single peak which is sharper than in the $\operatorname{SmA}_{(\mathrm{P})}$ phase and similar to polarization peaks usually observed in $\mathrm{SmAP}_{\mathrm{R}}$ phases, ${ }^{\mathbf{1 1}}$ but still relatively broad compared to typical $\mathrm{SmAP}_{\mathrm{F}}$ and $\mathrm{SmCP}_{\mathrm{F}}$ phases. ${ }^{\mathbf{1 0 2 0}}$ The presence of polar domains with relatively long coherence length is in line with dielectric studies indicating a high dielectric strength in this temperature range (Fig. 7b). Phase biaxiality is thought to arise from a tilt of the molecules $\left(\Delta n_{\mathrm{t}}\right)$, coupled with a restricted rotation around the long axis $\left(\Delta n_{\mathrm{b}}\right)$ (Fig. 9). Also the textures are in line with a tilted organization. The schlieren texture observed in the homeotropic aligned samples of this phase is distinct from those typically observed for orthogonal $\mathrm{SmA}_{\mathrm{b}}$ phases, which are characterized by a stripe pattern typically occurring in the homeotropic samples; ${ }^{21}$ such a stripe pattern is absent for $1 /$ 14. Also the presence of stable (not vanishing) four brush disclinations in the schlieren textures (see Fig. $\mathrm{S} 4 \dagger$ ) is not in line with a non-tilted $\mathrm{SmA}_{\mathrm{b}}$-like structure. ${ }^{7,22}$ This confirms the presence of a molecular tilt, though in planar textures the extinction crosses remain parallel to the polarizers (Fig. 6c). This might be caused by a not exclusively synclinic, but also anticlinic coupling of the tilt in adjacent layers, caused by the only weak layer coupling in this weakly tilted smectic phase.

3.7.3 $\operatorname{SmC}_{\mathbf{S}} \mathbf{P}_{\mathbf{A}}$ phase. Major changes take place in the temperature range between $133{ }^{\circ} \mathrm{C}$ and $110{ }^{\circ} \mathrm{C}$ on cooling. XRD indicates a decrease of $d$ which is a clear indication of a more significant increase of the tilt (Fig. 8c, region b) which according to optical investigations (Fig. 6e) become uniformly synclinic in the $\mathrm{SmC}_{\mathrm{s}} \mathrm{P}_{\mathrm{A}}$ phase. Dielectric investigations show a further noncontinuous strong rise of the dielectric strength up to $\sim 48$ (Fig. 7b). There is a jump in polarization values and two polarization current peaks indicate antiferroelectric switching (Fig. 4g). This confirms a synclinic tilted polar SmC phase $\left(\mathrm{SmC}_{\mathrm{S}} \mathrm{P}_{\mathrm{A}}\right)$ with only $\sim 10^{\circ}$ optical tilt and even smaller XRD tilt (probably $<5^{\circ}$ ). Even in this phase the observed tilt is unusually small for a bent-core molecule and provides an only weak layer coupling, giving rise to a series of very unusual properties of this $\mathrm{SmC}_{\mathrm{S}} \mathrm{P}_{\mathrm{A}}$ phase, especially in the vicinity of the $\mathrm{SmCP}_{\mathrm{R}}-\mathrm{SmC}_{\mathrm{S}} \mathrm{P}_{\mathrm{A}}$ phase transition where tilt and polar coherence length are the smallest and hence the layer coupling is the weakest (tailing between 133 and $115^{\circ} \mathrm{C}$, see Fig. 1). Firstly, in homeotropically aligned samples of the $\mathrm{SmC}_{\mathrm{S}} \mathrm{P}_{\mathrm{A}}$ phase an inversion of
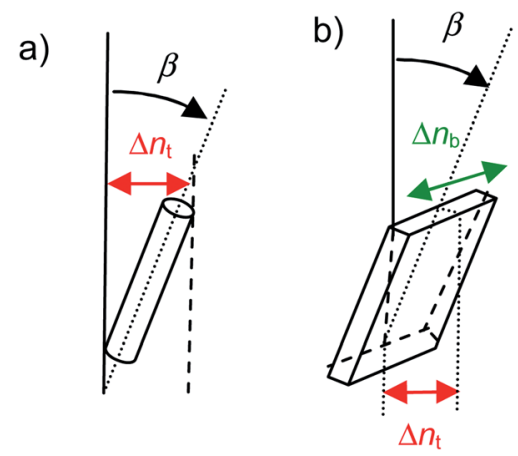

Fig. 9 Illustration of the contributions of tilt $\left(\Delta n_{t}\right)$ and restricted molecular rotation $\left(\Delta n_{b}\right)$ to birefringence; (a) shows the case of a smectic phase formed by molecules which are rotationally disordered around the long axis; here birefringence is determined by $\Delta n_{\mathrm{t}}$, which increases with growing tilt $\beta$; (b) shows the situation for a molecule with restricted rotation around the long axis; in this case $\Delta n_{\mathrm{t}}$ competes with $\Delta n_{\mathrm{b}}$ and if the tilt $\beta$ is small, then $\Delta n_{\mathrm{b}}$ can dominate $\left(\Delta n_{\mathrm{b}}>\Delta n_{\mathrm{t}}\right)$. 
birefringence (Fig. $2 \mathrm{c}-\mathrm{h}$ ) occurs at $\sim 130-132{ }^{\circ} \mathrm{C}$, i.e. immediately below the $\mathrm{SmCP}_{\mathrm{R}}-\mathrm{SmC}_{\mathrm{S}} \mathrm{P}_{\mathrm{A}}$ transition.

The inversion of birefringence in homeotropic samples is likely to be due to a competition between optical biaxiality caused by tilt $\left(\Delta n_{\mathrm{t}}\right)$ and biaxiality caused by the increasing restriction of the rotation of the molecules around their long axes $\left(\Delta n_{\mathrm{b}}\right)$. As in bent-core molecules the polar axis is perpendicular to the tilt direction of the molecular bending plane, these two contributions to phase biaxiality have opposite sign and at the crossover can extinguish each other (Fig. 9). This is believed to be the origin of the inversion of birefringence. As phase biaxiality due to tilt $\left(\Delta n_{\mathrm{t}}\right)$ is assumed to dominate in the $\mathrm{SmCP}_{\mathrm{R}}$ phase it is thought that the increasing polar coupling further restricts the rotation around the long axis, leading to a growing importance of $\Delta n_{\mathrm{b}}$. Because the tilt is extremely small in the $\mathrm{SmCP}_{\mathrm{R}}$ phase the birefringence in this phase is also very small (see Fig. 2c). As the tilt remains relatively small, the growing $\Delta n_{\mathrm{b}}$ can become larger than $\Delta n_{\mathrm{t}}$ after the inversion point with $\Delta n_{\mathrm{b}}=\Delta n_{\mathrm{t}}$. The absolute value $|\Delta n|$ further increases after the inversion point and below a certain temperature $|\Delta n|$ can become larger than in the $\mathrm{SmCP}_{\mathrm{R}}$ phase (Fig. $2 \mathrm{~g}$ ).

The weak layer coupling is also responsible for the easy formation of other mesophases $\left(\mathrm{M}_{1}\right.$ and $\left.\mathrm{SmCP}_{\alpha}\right)$, competing with the $\mathrm{SmC}_{\mathrm{S}} \mathrm{P}_{\mathrm{A}}$ phase. The tendency for formation of these phases is the highest immediately below the $\mathrm{SmCP}_{\mathrm{R}}$ phase. With decreasing temperature, i.e. with growing domain size and increasing layer coupling, the $\mathrm{SmC}_{\mathrm{S}} \mathrm{P}_{\mathrm{A}}$ structure becomes more dominating and is exclusively found in the temperature range between 110 and $115{ }^{\circ} \mathrm{C}$. On heating the preformed $\mathrm{SmC}_{\mathrm{S}} \mathrm{P}_{\mathrm{A}}$ phase can be retained up to $125{ }^{\circ} \mathrm{C}$. Above this temperature it becomes metastable and is replaced by the $\mathrm{SmCP}_{\alpha}$ phase if sufficiently slow heating rates are used.

The observation that the dielectric strength $\delta \varepsilon_{2}$ further increases in the $\mathrm{SmC}_{\mathrm{S}} \mathrm{P}_{\mathrm{A}}$ temperature range until the phase transition $\mathrm{SmC}_{\mathrm{S}} \mathrm{P}_{\mathrm{A}}-\mathrm{SmC}_{\mathrm{a}}^{\prime} \mathrm{P}_{\mathrm{A}}$ is reached at $110{ }^{\circ} \mathrm{C}$ indicates that in the $\mathrm{SmC}_{\mathrm{S}} \mathrm{P}_{\mathrm{A}}$ phase region no uniformly polar layers are formed. It seems that also the $\mathrm{SmC}_{\mathrm{S}} \mathrm{P}_{\mathrm{A}}$ phase is composed of polar $\mathrm{SmC}_{\mathrm{S}} \mathrm{P}_{\mathrm{F}}$ domains. Though the coherence length of these domains is much larger than in the $\mathrm{SmCP}_{\mathrm{R}}$ phase, such domains are still present and the further growth of the $\mathrm{SmC}_{\mathrm{S}} \mathrm{P}_{\mathrm{F}}$ domains in the $\mathrm{SmC}_{\mathrm{S}} \mathrm{P}_{\mathrm{A}}$ region is indicated by the growth of $\delta \varepsilon_{2}$ (Fig. 7b). So, the $\mathrm{SmC}_{\mathrm{S}} \mathrm{P}_{\mathrm{A}}$ phase appears to be not the classical type with a strictly antipolar organization between the individual layers, rather there appears to be $\operatorname{SmC}_{\mathrm{S}} \mathrm{P}_{\mathrm{F}}$ domains which adopt an on average synclinic and antipolar correlation (Fig. 10c). This structure can be described as $\left(\operatorname{SmC}_{\mathrm{S}} \mathrm{P}_{\mathrm{F}}\right)_{\mathrm{s}} \mathrm{P}_{\mathrm{A}}$.

3.7.4 $\mathrm{SmCP}_{\alpha}$ phase. The most interesting phase is probably the optically uniaxial smectic phase, showing antiferroelectric switching with relatively sharp polarization peaks, occurring below the $\mathrm{SmCP}_{\mathrm{R}}$ phase and competing with the $\mathrm{SmC}_{\mathrm{s}} \mathrm{P}_{\mathrm{A}}$ phase. Uniaxiality of polar smectic phases would only be possible if the correlation between the layers is randomized ( $P_{R}$ phases), or helical $\left(\mathrm{P}_{\alpha}\right)$. Lamellar structures with uniform polar direction in the layers, but random polar correlation between the layers or with a regular change of polar direction distinct from $0^{\circ}$ and $180^{\circ}$ were theoretically predicted for orthogonal smectic phases. ${ }^{13,23}$ This type of smectic phases involves distinct structures

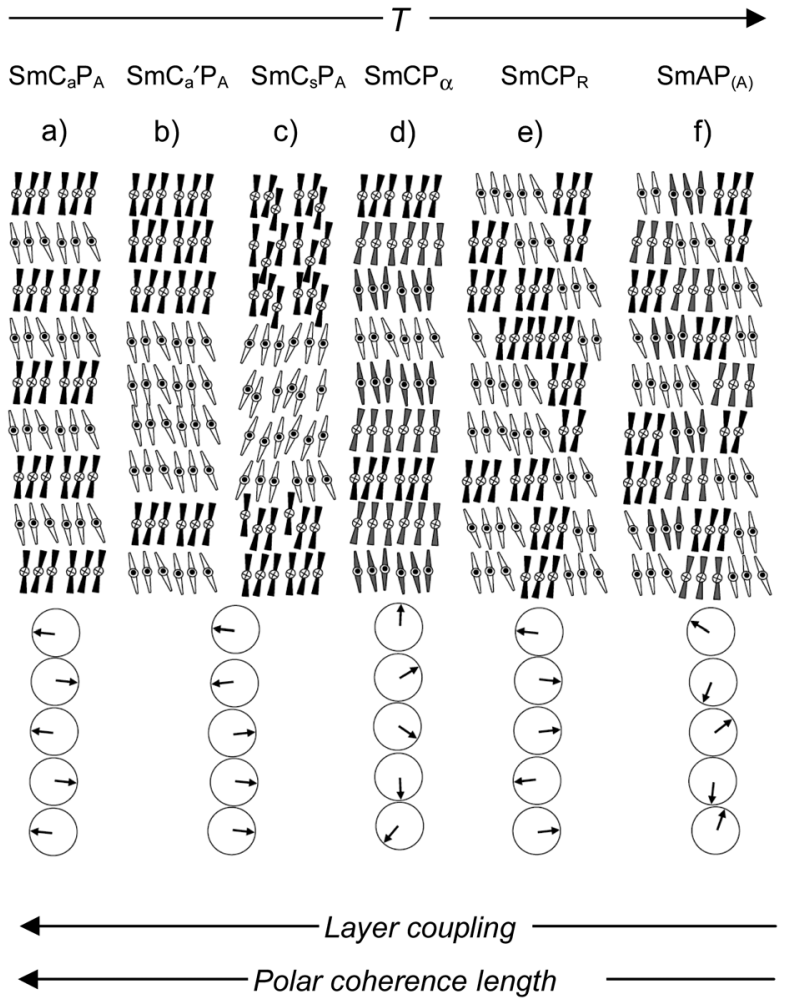

Fig. 10 Illustration of molecular arrangements assumed for the local and long range polar smectic phases observed for $1 / 14$ upon changing temperature; (a)-(f) side views on the layers; different gray scales indicates distinct polar directions (those in black/white are more or less perpendicular to the projection plane, those in gray are inclined by different angles); side views on the layers are shown at the top and at the bottom the polar directions in adjacent domains/layers is schematically shown as top views, each cycle represents a subsequent layer; arrows in the cycles indicate the polar direction in the layers.

$\left(\mathrm{SmAP}_{\mathrm{R}}, \mathrm{SmAP}_{2}\right.$ and $\left.\mathrm{SmAP}_{\alpha}\right)$ representing new types of smectic A phases. In these phases the change of the direction of the inplane polarization vectors in adjacent layers has the same sign in $\mathrm{SmAP}_{\alpha}$, has opposite sign in $\mathrm{SmAP}_{2}$ and is randomized in $\operatorname{SmAP}_{\mathrm{R}}$. Only the phases $\operatorname{SmAP}_{\alpha}$ and $\operatorname{SmAP}_{\mathrm{R}}$ are uniaxial whereas $\mathrm{SmAP}_{2}$ is biaxial. A $\mathrm{SmAP}_{\alpha}$ type of these phases was recently suggested for the related alkyl substituted compound $2 /$ 14 (Scheme 1). ${ }^{13}$ It is likely that a similar phase structure can also be formed by weakly tilted and hence weakly coupled polar SmC phases of bent-core mesogens. Hence, the layer correlation could be random $\left(\mathrm{P}_{\mathrm{R}}\right)$ or $\mathrm{P}_{\alpha}$-like in this uniaxial polar SmC phase of $1 / 14$. Between 133 and $130^{\circ} \mathrm{C}$ there is a coexistence of a broad single polarization current peak with a double peak (Fig. $4 \mathrm{~g}$ ). In this temperature range the $\mathrm{P}_{\mathrm{R}}$ structure, showing only one relatively broad polarization peak, could probably coexist with the antiferroelectric switching uniaxial SmC phase $\left(\operatorname{SmCP}_{\alpha}\right)$. However, the switching is exclusively antiferroelectric in the temperature range between 115 and $130{ }^{\circ} \mathrm{C}$ (Fig. 4h). Hence, the structure of this polar smectic phase is most probably $\operatorname{SmCP}_{\alpha}$, a tilted version of the $\operatorname{SmAP}_{\alpha}$ phase and related to the $\mathrm{SmC}^{*}{ }_{\alpha}$ phase occurring at the $\mathrm{SmC}^{*}-\mathrm{SmA}^{*}$ transition of chiral rod-like molecules with small tilt. ${ }^{24}$ In this phase the in-plane polarization direction rotates uniformly from layer to layer by a fixed 
angle (Fig. 10d). In contrast to the previously reported $\operatorname{SmAP}_{\alpha}$ phase of compound 2/14 (ref. 13) no uniaxial state could be induced in the homeotropically aligned $\mathrm{SmCP}_{\alpha}$ phase of $1 / 14$ under an in-plane electric field (up to $10 \mathrm{~V} \mathrm{\mu m}^{-1}$ ). It is possible that the angle of the polar vector in adjacent layers of the $\mathrm{SmCP}_{\alpha}$ phase is smaller than $90^{\circ}$ in the ground state. In this case increasing the applied field leads directly to the field induced $\mathrm{SmC}_{\mathrm{S}} \mathrm{P}_{\mathrm{F}}$ state without crossing an optically isotropic $90^{\circ}$ twisted state.

3.7.5 $\mathbf{M}_{1}$-phase. The structure of the birefringent $\mathrm{M}_{1}$ phase, competing with the uniaxial $\mathrm{SmCP}_{\alpha}$ phase is not clear. Its high birefringence, viscosity and the mosaic-like appearance of the texture (Fig. 3) are indications of the presence of additional order. This could be caused by a correlation and coupling of the layers or polar domains either by register on a $2 \mathrm{D}$ or $3 \mathrm{D}$ lattice or it could be the consequence of layer modulations resulting from the growing coherence length of the synpolar (ferroelectric) domains. That no indications for additional order can be found in the XRD patterns might be due to a large wave length of these modulations, a not well developed long range correlation or due to the coexistence with other phases, so that under the conditions of these investigations the $\mathrm{SmC}_{\mathrm{S}} \mathrm{P}_{\mathrm{A}}$ or $\mathrm{SmCP}_{\alpha}$ phases dominate.

3.7.6 $\mathrm{SmC}_{\mathbf{a}}^{\prime} \mathbf{P}_{\mathbf{A}}$ phase. In this phase, occurring at a continuous phase transition at $T=110{ }^{\circ} \mathrm{C}$ the polar order is almost long range. The tilt is still relatively small and the packing density increases on further cooling as indicated by XRD ( $d$ values of the layer reflection increases, see Fig. 8c, region c), the polarization further rises in this temperature range and the layer correlation appears to be anticlinic (Fig. $6 \mathrm{~g}$ and i). The dielectric strength decreases, but is still large $\left(\delta \varepsilon_{2}=35-48\right.$, see Fig. 7b), in line with a long range polar correlation, which however, is still not completely uniform throughout the layers. Close to $110{ }^{\circ} \mathrm{C}$ the switching takes place on a cone as typical for polar smectic phases of bent core molecules and it changes to a rotation around the long axis with further decreasing temperature (Fig. 6g-j).

There is no enthalpy associated with the $\operatorname{SmC}_{\mathrm{s}} \mathrm{P}_{\mathrm{A}}-\operatorname{SmC}_{\mathrm{a}}^{\prime} \mathrm{P}_{\mathrm{A}}$ transition. Hence, it is continuous and therefore it is likely that this transition is not associated with an abrupt change from the synclinic to anticlinic interlayer correlation between adjacent layers. In the $\mathrm{SmC}_{\mathrm{S}} \mathrm{P}_{\mathrm{A}}$ range the polar domain structure in the layers allows fluctuations between the layers which entropically favor the synclinic layer correlation. As the polar domains become long range at the $\operatorname{SmC}_{\mathrm{S}} \mathrm{P}_{\mathrm{A}}-\mathrm{SmC}_{\mathrm{a}}^{\prime} \mathrm{P}_{\mathrm{A}}$ transition the interlayer interfaces become sharper and these fluctuations are reduced and then also some anticlinic correlation can appear. The number of emerging anticlinic interfaces might be relatively small, but as soon as the thickness of the uniform synclinic layer stacks falls below a length smaller than the wave length of light, this structure appears optically like an anticlinic tilted smectic phase with extinction crosses parallel to the polarizers. The overall phase structure could thus be descried as $\left(\mathrm{SmC}_{\mathrm{S}} \mathrm{P}_{\mathrm{F}}\right)_{\mathrm{a}} \mathrm{P}_{\mathrm{A}}$, a slightly tilted polar smectic phase composed of $\mathrm{SmC}_{\mathrm{S}} \mathrm{P}_{\mathrm{F}}$ domains or layer stacks having an antipolar and anticlinic correlation (Fig. 10b), the prime in the phase assignment $\mathrm{SmC}_{\mathrm{a}}^{\prime} \mathrm{P}_{\mathrm{A}}$ is used here to indicates this type of structure. Due to the small tilt, which is difficult to indicate by XRD and the synclinic structure with anticlinic defects, leading to a texture with extinction crosses parallel to the polarizers (Fig. $6 \mathrm{~g}$ and i) this weakly tilted $\mathrm{SmC}_{\mathrm{a}}^{\prime} \mathrm{P}_{\mathrm{A}}$ phase is extremely difficult to distinguish from the nontilted $\mathrm{SmAP}_{\mathrm{A}}$ phases, especially if the switching takes place by rotation around the long axis, which does not change the position of the extinctions, as also expected for the switching of $\mathrm{SmAP}_{\mathrm{A}}$ phases. This leads to the conclusion that at least some of the previously reported $\mathrm{SmAP}_{\mathrm{A}}$ phases could in fact represent such weakly tilted and weakly correlated $\left(\mathrm{SmC}_{\mathrm{S}} \mathrm{P}_{\mathrm{F}}\right)_{\mathrm{a}} \mathrm{P}_{\mathrm{A}}$ phases. Further confirmation of the proposed molecular organization could possibly be gained by investigation of freely suspended films, though for these weakly correlated smectic phases the kind of interfaces might have a significant impact on the phase structure, so that it is not clear if these films would be identical with the bulk structures.

3.7.7 $\mathbf{S m C}_{\mathbf{a}} \mathbf{P}_{\mathbf{A}}$ phase. This low temperature phase occurs below $\sim 75{ }^{\circ} \mathrm{C}$ at a continuous transition (Fig. 1) which is indicated by further textural changes (Fig. $2 \mathrm{i}$ and $\mathrm{j}$ ). There is a rapid decrease of the dielectric strength $\delta \varepsilon_{2}$ at this temperature (Fig. 7c) as typical for the transition to $\mathrm{B}_{2}$-like polar smectic phases with uniform polarity in the individual layers. The polarization peaks are merged to only one (Fig. S5 $\dagger$ ), presumably due to the relatively high viscosity, which also explains that exclusively switching around the long axis is observed in this phase (Fig. 6k and l). This phase appears to be more similar to the classical $\mathrm{B}_{2}$-type $\mathrm{SmC}_{\mathrm{a}} \mathrm{P}_{\mathrm{A}}$ phase characterized by a high density of anticlinic and antipolar interfaces, most probably formed by single layers with alternating polar vector (Fig. 10a).

3.7.8 Overall phase sequence. The majority of transition enthalpy in the LC range (see Fig. 1) is found for the Iso-SmA transition $\left(9.3 \mathrm{~kJ} \mathrm{~mol}^{-1}\right)$ which is in line with the presence of polar order already in the SmA phase, but the polar domains have a short coherence length which grows on cooling, leading to a transition from a short ordinary SmA region close to the clearing temperature to a broad paraelectric $\operatorname{SmA}_{(\mathrm{P})}$ region, where the correlation length of the polar domains continuously increases. Above a certain domain size tilt and phase biaxiality emerge ( $\mathrm{SmCP}_{\mathrm{R}}$ phase) though polar order is still randomized between the domains. In this $\mathrm{SmCP}_{\mathrm{R}}$ phase an exponential growth of the polar domains takes place, which leads to the next first order phase transition at $\sim 133{ }^{\circ} \mathrm{C}\left(1.7 \mathrm{~kJ} \mathrm{~mol}^{-1}\right)$. This phase transition is associated with a significant growth of the coherence length of the polar domains, though uniformly polar layers are not achieved at this transition. In the $\mathrm{SmC}_{\mathrm{S}} \mathrm{P}_{\mathrm{A}}$ range the polar domain grow further in size and this gives rise to a strengthening of the layer correlation with decreasing temperature. Directly below the phase transition, when layer coupling is still very weak, additional phases $\left(\mathrm{M}_{1}, \mathrm{SmCP}_{\alpha}\right)$ could occur, which are removed at lower temperature when layer coupling becomes stronger. The polar domains become nearly long range at the $\operatorname{SmC}_{\mathrm{S}} \mathrm{P}_{\mathrm{A}}-\mathrm{SmC}_{\mathrm{a}}^{\prime} \mathrm{P}_{\mathrm{A}}$ transition and anticlinic interlayer interfaces emerge. The number of anticlinic interfaces increases in the $\mathrm{SmC}_{\mathrm{a}}^{\prime} \mathrm{P}_{\mathrm{A}}$ phase range and polar order becomes macroscopic, with anticlinic interlayer correlation in the phase assigned as $\mathrm{SmC}_{\mathrm{a}} \mathrm{P}_{\mathrm{A}}$. A sketch of this phase sequence is shown in Fig. 10. 
According to dielectric results all phases with exception of $\mathrm{SmC}_{\mathrm{a}} \mathrm{P}_{\mathrm{A}}$ at lowest temperature appear to be formed by ferroelectric domains (Fig. 7b). The polar domains are thought to have $\mathrm{SmC}_{\mathrm{S}} \mathrm{P}_{\mathrm{F}}$ structure with relatively small tilt. With decreasing temperature the transition from local to macroscopic polar order is coupled with the emergence of a macroscopic tilt above a certain threshold of the polar coherence length. Paraelectricantiferroelectric transitions have previously been studies by Gorecka et $a .^{25}$ and Eremin et $a .^{26}$ for other bent-core materials with $\mathrm{SmA}_{-}-\mathrm{SmAP}_{\mathrm{A}}-\mathrm{SmC}_{\mathrm{S}} \mathrm{P}_{\mathrm{A}}, \mathrm{SmA}-\mathrm{SmC}-\mathrm{SmC}_{\mathrm{S}} \mathrm{P}_{\mathrm{A}}$ and $\mathrm{SmA}-$ $\mathrm{SmAP}_{\mathrm{A}}$ phase sequences. These investigations indicated weak layer coupling and strong critical fluctuations of polarization and tilt at the paraelectric-antiferroelectric transition. In our case, due to the smaller tilt, the layer coupling appears to be even weaker, so that additional phases $\left(\mathrm{SmCP}_{\mathrm{R}}, \mathrm{M}_{1}, \mathrm{SmCP}_{\alpha}\right)$ were observed at this transition. The coupling between polarization and tilt in the LC phases formed by achiral bent-core molecules, ${ }^{25,26}$ i.e. the induction of tilt by polar order appears to be the main driving force for the development of a small tilt in the smectic phases of compound 1/14.

It is in principle possible, that the local $\operatorname{SmC}_{\mathrm{S}} \mathrm{P}_{\mathrm{F}}$ domain structure is already present in the $\operatorname{SmA}_{(\mathrm{P})}$ range where it is completely randomized, similar to de Vries-like SmA phases (Fig. 10f). The tilted organization in the polar domains would improve the core packing and could strengthen the local polar order. The presence of only a small tilt is favourable for a complete randomization of the $\mathrm{SmC}_{\mathrm{S}} \mathrm{P}_{\mathrm{F}}$ domains in the temperature range of the $\operatorname{SmAP}_{(\mathrm{P})}$ phase. The relatively broad diffuse XRD wide angle scattering (see Fig. 8) supports this possibility, also the relatively large difference between $d$ and $L_{\mathrm{mol}}$ as well as the rather small decrease of $d(\Delta d=0.03 \mathrm{~nm})$ during the $\mathrm{SmA}_{(\mathrm{P})}-\mathrm{SmCP}_{\mathrm{R}}-\mathrm{SmC}_{\mathrm{S}} \mathrm{P}_{\mathrm{A}}$ transitions would be in line with such a model. The $\operatorname{SmC}_{\mathrm{S}} \mathrm{P}_{\mathrm{F}}$ domains continuously grow with decreasing temperature and at the transition to the $\mathrm{SmCP}_{\mathrm{R}}$ phase the local $\mathrm{SmC}_{\mathrm{S}} \mathrm{P}_{\mathrm{F}}$ domains registers in a biaxial mode but with still randomized polar direction, i.e. the polar directions are preferably parallel/antiparallel with relatively low orientational order parameter of the polar vector (Fig. 10e). In the $\mathrm{SmCP}_{\alpha}$ phase there appears to be a competition between tilt correlation and polar correlation, and hence, next-nearestneighbour interactions, favoring a nonparallel $\mathrm{P}_{\alpha}$-like alignment of the polar vectors, become dominating (Fig. 10d). Tilt becomes uniform and correlation of the domains becomes antipolar at the transition to the $\operatorname{SmC}_{\mathrm{S}} \mathrm{P}_{\mathrm{A}}$ phase (Fig. 10c). Further increase of the polar coherence length leads, as described above, to the $\operatorname{SmC}_{\mathrm{a}}^{\prime} \mathrm{P}_{\mathrm{A}}$ and $\operatorname{SmC}_{\mathrm{a}} \mathrm{P}_{\mathrm{A}}$ phases with increasing number of anticlinic correlations (Fig. 10a and $b$ ).

3.7.9 Comparison with related bent-core mesogens. As pointed out above, the special mode of development of polar order is likely to be related to the unusual small tilt of 1/14 in its mesophases, compared to other bent-core molecules. In contrast to the terephthalate $1 / 14$, related phenylbenzoates, like 3/14 (ref. 9 and 27) with two reversed ester groups and also similar compounds with azobenzene wings, like 4/14 (ref. 28) form exclusively tilted phases with strong tilt (Scheme 2). For the azobenzene compound $4 / 14$, for example, the tilt is much larger $\left(\sim 30^{\circ} \mathrm{XRD}\right.$ tilt $)$ and in this case layer correlation is much stronger. For compound 4/14 a uniform synclinic tilt correlation is already achieved in the phase region of the paraelectric $\mathrm{SmC}_{(\mathrm{P})}^{[*]}$ phase. ${ }^{28}$ At the transition from the paraelectric $\mathrm{SmC}_{(\mathrm{P})}^{[*}$ phase to the $\mathrm{SmC}_{\mathrm{S}} \mathrm{P}_{\mathrm{R}}^{[*]}$ phase local polar order develops in synclinic $\mathrm{SmC}_{\mathrm{S}} \mathrm{P}_{\mathrm{F}}$-domains with overall randomized polar direction. In contrast to the $\mathrm{SmCP}_{\mathrm{R}}$ phase reported here, the strongly tilted $\mathrm{SmC}_{(\mathrm{P})}^{[*]}$ and $\mathrm{SmC}_{\mathrm{S}} \mathrm{P}_{\mathrm{R}}^{[*]}$ phases of $4 / 14$ are capable of forming surface stabilized conglomerates of chiral domains (therefore $\left.\left[{ }^{*}\right]\right) .{ }^{28 b}$ The absence of such macroscopic chiral domains in the $\mathrm{SmCP}_{R}$ phase of $1 / 14$ is in line with a much smaller tilt and the resulting weak layer coupling. Due to the strong tilt also the uniaxial polar smectic phase $\left(\mathrm{SmCP}_{\alpha}\right)$ is missing for compound $4 / 14$ with azobenzene wings, but a highly viscous phase, similar to $M_{1}$, is also found for this compound. Similar to $1 / 14$ a synclinic polar smectic phase is formed below the randomized polar phase of the azobenzene $4 / 14$, which in this case reveals ferroelectric order in free standing films (therefore it was assigned as $\mathrm{SmC}_{\mathrm{S}} \mathrm{P}_{\mathrm{F}}$ in this case); ${ }^{28 \boldsymbol{b}}$ this phase shows antiferroelectric switching in ITO cells, similar to the $\mathrm{SmC}_{\mathrm{S}} \mathrm{P}_{\mathrm{A}}$ phase of compound 1/14. This further supports the proposed $\mathrm{SmC}_{\mathrm{S}} \mathrm{P}_{\mathrm{F}}$ domains structure (Fig. 10c) of the $\mathrm{SmC}_{\mathrm{S}} \mathrm{P}_{\mathrm{A}}$ phase of compound $1 / 14$ reported here.

It appears that for compounds like $3 / 14$ and $4 / 14$, as for most other known bent-core mesogens, the strong tilt is inherent, i.e. it is due to the molecular structure, inherently preferring a tilted organization, whereas for the terephthalate $1 / 14$ the small tilt is polarity induced, as a tilted organization allows a denser core packing which is favorable for polar order.

Comparison with the related alkyl substituted compound 2/ 14 (Scheme 1), forming the non-tilted $\operatorname{SmAP}_{\alpha}$ phase instead of the $\mathrm{SmCP}_{\alpha}$ phase and the uniaxial $\operatorname{SmAP}_{\mathrm{R}}$ phase above the $\mathrm{P}_{\alpha}$ phase, indicates that an increased tendency for tilted organization is provided by replacing the alkyl chains by alkoxy chains.

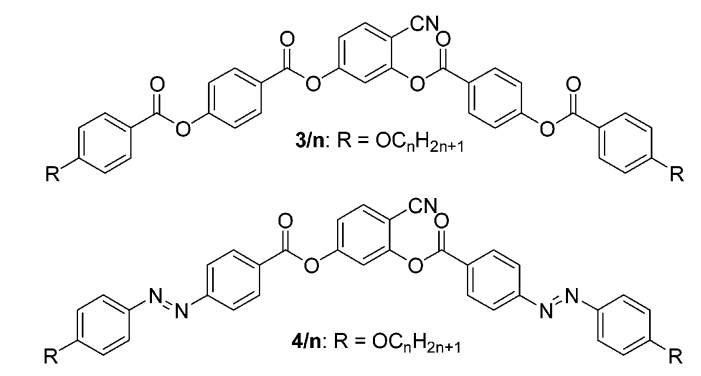

3/14: $\operatorname{Cr} 103\left(\mathrm{SmCP}_{\mathrm{A}}\right.$ " $68 \mathrm{SmCP}_{\mathrm{A}}^{\prime} 75 \mathrm{SmCP}_{\mathrm{A}}$ 94) SmC $109 \mathrm{~N}_{\text {CybC }} 129$ Iso

4/14: $\mathrm{Cr} 72 \mathrm{SmC}_{\mathrm{s}} \mathrm{P}_{\mathrm{A}} 76 \mathrm{M}_{1} 78 \mathrm{SmC}_{\mathrm{s}} \mathrm{P}_{\mathrm{F}} 90 \mathrm{SmC}_{\mathrm{s}} \mathrm{P}_{\mathrm{R}}^{[*]} 102 \mathrm{SmC}_{(\mathrm{P})}^{\left[{ }^{[*]}\right.} 139.5 \mathrm{~N}_{\mathrm{cybc}} 140$ Iso

Scheme 2 4-Cyanoresorcinol based bent-core mesogen related to $1 / 14$, but with reversed ester groups in the wings (3/14) and with ester groups replaced by azo groups (4/14), their mesophases and transition temperatures $\left(T /{ }^{\circ} \mathrm{C}\right)$; abbreviations: $\mathrm{SmC}=$ nonpolar tilted smectic phase; $\mathrm{SmCP}_{\mathrm{A}}=$ antiferroelectric $\mathrm{SmC}$ phase; $\mathrm{SmCP}_{\mathrm{A}}^{\prime}, \mathrm{SmCP}_{\mathrm{A}}^{\prime \prime}=$ $\mathrm{SmCP}_{\mathrm{A}}$ phase subtypes with non-specified structure; $\mathrm{SmC}_{(\mathrm{P})}^{[*]}=$ paraelectric SmC phase; $\mathrm{SmC}_{\mathrm{S}} \mathrm{P}_{\mathrm{R}}^{[*]}=$ synclinic tilted $\mathrm{SmC}$ phase with randomized polar order, [*] indicates that these phases form a conglomerate of chiral domains after homeotropic alignment; $\mathrm{SmC}_{\mathrm{s}} \mathrm{P}_{\mathrm{F}}$ $=$ synclinic tilted polar SmC phase showing ferroelectric switching in free standing films; $\mathrm{N}_{\mathrm{cybc}}=$ cybotactic nematic phase composed of small clusters of a SmC phase; for other abbreviation, see Scheme 1. 
Nevertheless, there is the possibility that also the $\operatorname{SmAP}_{\mathrm{A}}$ phase of 2/14 might be a slightly tilted phase, which requires further investigation of this series of compounds.

The key feature of compound 1/14 is the weak layer coupling, arising from an unusual small tilt. For strongly tilted phases of bent-core mesogens layer decoupling could be alternatively be achieved by nano-segregation of flexible silyl end groups. For such compounds the smectic phases show ferroelectric switching after surface stabilization..$^{20,29,30}$

\section{Conclusions and summary}

Compound 1/14 forms a wide variety of different smectic phases (see Scheme 1 and Fig. 1) which allows a unique study of the combined development of tilt correlation and polar correlation depending on temperature. Based on XRD studies and optical investigations it was shown that all smectic phases occurring below $146{ }^{\circ} \mathrm{C}$ represent weakly tilted smectic phases. This is in contrast to previous reports of the homologue 1/12 (ref. 9) and related alkyl substituted compounds $2 / n^{\mathbf{1 3}}$ for which exclusively nontilted smectic phases ( $\mathrm{SmA}, \mathrm{SmAP}_{\mathrm{R}}, \mathrm{SmAP}_{\mathrm{A}}$ and $\operatorname{SmAP}_{\alpha}$ ) were considered (see Scheme 1). However, based on the investigations reported in this paper the possibility of formation of weakly tilted phases must also be taken into consideration in the discussion of the LC phases of these compounds, especially for compounds with relatively long alkyl chains. Thus, the tilted $\mathrm{SmC}_{\mathrm{a}}^{\prime} \mathrm{P}_{\mathrm{A}}$ and $\mathrm{SmC}_{\mathrm{a}} \mathrm{P}_{\mathrm{A}}$ phases must be considered as possible alternative structures for some of the previously reported $\mathrm{SmAP}_{\mathrm{A}}$ phases.

It is hypothesized that tilt in these smectic phases is not preliminary due to the molecular structure, rather it is a result of the polar packing. It appears to be only local in the paraelectric smectic phases with local polar order and becomes long range as the coherence length of the polar domains grows. This combination of emerging tilt and growing coherence length of polar domains leads to a weak layer coupling and a competition between polar and tilt couplings, and this provides a source of new LC phases, namely a weakly tilted biaxial smectic phase with randomized polar order $\left(\mathrm{SmCP}_{\mathrm{R}}\right)$ and a $\mathrm{SmC}$ phase with a unique combination of antiferroelectric switching and optical uniaxiality, most probably representing a $\mathrm{SmCP}_{\alpha}$ phase with helical superstructure due to a regular change of the in-plane polarization vector between the layers by an angle between $>0^{\circ}$ and $<90^{\circ}$. Overall, the unprecedented sequence of a total of

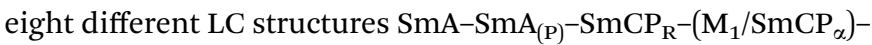
$\mathrm{SmC}_{\mathrm{S}} \mathrm{P}_{\mathrm{A}}-\mathrm{SmC}_{\mathrm{a}}^{\prime} \mathrm{P}_{\mathrm{A}}-\mathrm{SmC}_{\mathrm{a}} \mathrm{P}_{\mathrm{A}}$ in a single compound results from growing polar domains and tilt coupling. The coupling of polar order and tilt also suggests a possible de Vries-like structure of the paraelectric $\operatorname{SmA}_{(\mathrm{P})}$ phases and polarization randomized $\mathrm{SmAP}_{\mathrm{R}}$ phases.

The $\mathrm{SmCP}_{\mathrm{R}}$ phase can be considered as a new member of the series of "randomized" polar smectic phases, representing smectic phases with polar domains with appreciable size and sometimes occurring between the paraelectric and the macroscopic polar smectic phases of bent-core mesogens. Thus, the $\mathrm{SmCP}_{\mathrm{R}}$ phase might represent a link between the nontilted
$\mathrm{SmAP}_{\mathrm{R}}$ phases and the recently reported strongly tilted $\mathrm{SmC}_{\mathrm{S}} \mathrm{P}_{\mathrm{R}}^{[*]}$ phases. ${ }^{28}$

Moreover, the pronounced molecular biaxiality of bent-core mesogens and the resulting competition between the biaxiality caused by the tilt and by the restricted rotation around the long axis (molecular biaxiality), having orthogonal directions, can be considered as the reason for the observed inversion in the direction of birefringence. To the best of our knowledge, this is the first example being ported for such an inversion in birefringence of a mesophase formed by bent-core molecules.

It appears that for these weakly tilted and hence weakly coupled smectic phases the development of polar order is a complex process, involving competing interactions and frustration, thus providing the conditions for the formation of new phase structures. ${ }^{31}$ The models suggested for the phase sequence represent a likely possibility which fits with the presented investigations and the present state of knowledge in this field, though further studies, especially of the $\mathrm{M}_{1}$ and $\mathrm{SmCP}_{\alpha}$ phases and the development of the distinct phase structures depending on the alkyl chain length, are required to arrive at a final conclusion. Nevertheless, this work provides a significant step forwards in the understanding of the modes of development of polar order in soft matter systems.

\section{Acknowledgements}

The work was supported by the EU within FP7, collaborative project BIND (grant no. 216025); M. Alaasar acknowledges the support by the Alexander von Humboldt Foundation for the research fellowship at Martin-Luther University Halle-Wittenberg, Germany.

\section{References}

1 (a) R. A. Reddy and C. Tschierske, J. Mater. Chem., 2006, 16, 907; (b) H. Takezoe and Y. Takanishi, Jpn. J. Appl. Phys., 2006, 45, 597; (c) A. Eremin and A. Jakli, Soft Matter, 2013, 9, 615.

2 H. Takezoe, Top. Curr. Chem., 2012, 318, 303.

3 L. E. Hough, M. Spannuth, M. Nakata, D. A. Coleman, C. D. Jones, G. Dantlgraber, C. Tschierske, J. Watanabe, E. Körblova, D. M. Walba, J. E. Maclennan, M. A. Glaser and N. A. Clark, Science, 2009, 325, 452.

4 (a) T. Niori, T. Sekine, J. Watanabe, T. Furukawa and H. Takezoe, J. Mater. Chem., 1996, 6, 1231; (b) J. Etxebarria and M. B. Ros, J. Mater. Chem., 2008, 18, 2919.

5 D. R. Link, G. Natale, R. Shao, J. E. Maclennan, N. A. Clark, E. Körblova and D. M. Walba, Science, 1997, 278, 1924.

6 (a) C. Keith, M. Prehm, Y. P. Panarin, J. K. Vij and C. Tschierske, Chem. Commun., 2010, 46, 3702; (b) M. Nagaraj, Y. P. Panarin, J. K. Vij, C. Keith and C. Tschierske, Appl. Phys. Lett., 2010, 97, 213505; (c) Y. P. Panarin, M. Nagaraj, J. K. Vij, C. Keith and C. Tschierske, Europhys. Lett., 2010, 92, 26002.

7 H. R. Brand, P. E. Cladis and H. Pleiner, Macromolecules, 1992, 25, 7223.

8 (a) A. Eremin, S. Diele, G. Pelzl, H. Nadasi, W. Weissflog, J. Salfetnikova and H. Kresse, Phys. Rev. E, 2001, 64, 
051707; (b) R. A. Reddy and B. K. Sadashiva, J. Mater. Chem., 2004, 14, 310; (c) B. Glettner, S. Hein, R. A. Reddy, U. Baumeister and C. Tschierske, Chem. Commun., 2007, 2596.

9 L. Kovalenko, M. W. Schröder, R. A. Reddy, S. Diele, G. Pelzl and W. Weissflog, Liq. Cryst., 2005, 32, 857.

10 R. A. Reddy, C. Zhu, R. Shao, E. Körblova, T. Gong, Y. Shen, E. Garcia, M. A. Glaser, J. E. Maclennan, D. M. Walba and N. A. Clark, Science, 2011, 332, 72.

11 (a) Y. Shimbo, E. Gorecka, D. Pociecha, F. Araoka, M. Goto, Y. Takanishi, K. Ishikawa, J. Mieczkowski, K. Gomola and H. Takezoe, Phys. Rev. Lett., 2006, 97, 113901; (b) K. Gomola, L. Guo, E. Gorecka, D. Pociecha, J. Mieczkowski, K. Ishikawa and H. Takezoe, Chem. Commun., 2009, 6592; (c) C. Keith, M. Prehm, Y. P. Panarin, J. K. Vij and C. Tschierske, Chem. Commun., 2010, 46, 3702; (d) K. Gomola, L. Guo, D. Pociecha, F. Araoka, K. Ishikawa and H. Takezoe, J. Mater. Chem., 2010, 20, 7944; (e) M. Gupta, S. Datta, S. Radhika, B. K. Sadashiva and A. Roy, Soft Matter, 2011, 7, 4735.

12 An antiferroelectric switching SmA phase with randomized polar order, assigned as $\mathrm{SmAP}_{\mathrm{AR}}$, was previously reported for a 3-aminophenol derived bent-core mesogen. ${ }^{\mathbf{1 1 d}}$

13 (a) Y. P. Panarin, M. Nagaraj, S. Sreenilayam, J. K. Vij, A. Lehmann and C. Tschierske, Phys. Rev. Lett., 2011, 107, 247801; (b) S. Sreenilayam, Y. P. Panarin, J. K. Vij, M. Osipov, A. Lehmann and C. Tschierske, Phys. Rev. E, 2013, 88, 012504.

14 (a) G. S. Lee, Y.-J. Lee, S. Y. Choi, Y. S. Park and K. B. Yoon, J. Am. Chem. Soc., 2000, 122, 12151; (b) I. Wirth, S. Diele, A. Eremin, G. Pelzl, S. Grande, L. Kovalenko, N. Pancenko and W. Weissflog, J. Mater. Chem., 2001, 11, 1642.

15 S. Havriliak Jr and S. Negami, Polymer, 1967, 8, 161.

16 Though the transitions between $\mathrm{SmC}_{\mathrm{S}} \mathrm{P}_{\mathrm{A}}, \mathrm{SmCP}_{\alpha}$ and $\mathrm{M}_{1}$ are continuous and influenced by the surface conditions, we consider them as distinct phases instead of being different states of molecular ordering of a single phase, as their properties and optical textures are very different $\left(M_{1}\right.$ is highly viscous, whereas $\mathrm{SmC}_{\mathrm{S}} \mathrm{P}_{\mathrm{A}}$ and $\mathrm{SmCP}_{\alpha}$ are fluid; $\mathrm{M}_{1}$ and $\mathrm{SmC}_{\mathrm{S}} \mathrm{P}_{\mathrm{A}}$ are biaxial whereas $\mathrm{SmCP}_{\alpha}$ is uniaxial). Moreover, there is no clear evidence that their structures are solely induced by surface interactions or field-effects. It appears that kinetic effects are more important for the observed hysteresis in the transition temperatures between these phases. However, in addition to the reported phases, there are additional field induced states, occurring below $146{ }^{\circ} \mathrm{C}$ and induced by special wave forms of the applied electric field; these are not discussed herein. Also the point of inversion of the birefringence in the $\mathrm{SmC}_{\mathrm{S}} \mathrm{P}_{\mathrm{A}}$ range does not represent a phase transition.

17 In electro-optical experiments using ITO cells no indication of the formation of the $\mathrm{M}_{1}$ phase can be found.

18 If there would be a transition from a synclinic tilted to a nontilted $\mathrm{SmAP}_{\mathrm{A}}$ structure the birefringence of the texture at $0 \mathrm{~V}$ should not decrease but increase at the phase transition from $\mathrm{SmC}_{\mathrm{S}} \mathrm{P}_{\mathrm{F}}$ to $\mathrm{SmAP}_{\mathrm{A}}$ and also no field induced inclination of the extinctions could be expected. A re- entrance of a nontilted phase $\left(\mathrm{SmAP}_{\mathrm{A}}\right)$ could therefore be excluded.

19 M. Nakata, R.-F. Shao, J. E. Maclennan, W. Weissflog and N. A. Clark, Phys. Rev. Lett., 2006, 96, 067802.

20 (a) G. Dantlgraber, A. Eremin, S. Diele, A. Hauser, H. Kresse, G. Pelzl and C. Tschierske, Angew. Chem., Int. Ed., 2002, 41, 2408; (b) G. Dantlgraber, R. A. Reddy, A. Hauser, U. Baumeister and C. Tschierske, J. Am. Chem. Soc., 2006, 128, 3051; (c) C. Keith, R. A. Reddy, U. Baumeister and C. Tschierske, J. Am. Chem. Soc., 2004, 126, 14312; (d) C. Keith, R. A. Reddy, H. Hahn, H. Lang and C. Tschierske, Chem. Commun., 2004, 1898; (e) C. Keith, R. A. Reddy and C. Tschierske, Chem. Commun., 2005, 871; $(f)$ R. A. Reddy, U. Baumeister, C. Keith and C. Tschierske, J. Mater. Chem., 2007, 17, 62 .

21 (a) R. Pratibha, N. V. Madhusudana and B. K. Sadashiva, Eur. Phys. Lett., 2007, 80, 46001; (b) T. Hegmann, J. Kain, S. Diele, G. Pelzl and C. Tschierske, Angew. Chem., Int. Ed., 2001, 40, 887; (c) V. C. Yelamaggad, I. S. Shashikala, V. P. Tamilenthi, D. S. Shankar Rao, G. G. Nair and S. K. Prasad, J. Mater. Chem., 2008, 18, 2096.

22 Due to the randomized polar organization in the $\mathrm{SmCP}_{R}$ ground state this phase can be considered as a non-polar smectic phase.

23 D. Pociecha, M. Cepic, E. Gorecka and J. Mieczkowski, Phys. Rev. Lett., 2003, 91, 185501.

24 (a) V. Laux, N. Isaert, V. Faye and H. T. Nguyen, Liq. Cryst., 2000, 27, 81; (b) J. P. F. Lagerwall, Phys. Rev. E, 2005, 71, 051703.

25 (a) D. Pociecha, E. Gorecka, M. Cepic, N. Vaupotic, K. Gomola and J. Mieczkowski, Phys. Rev. E, 2005, 72, 060701(R); (b) D. Pociecha, E. Gorecka, M. Cepic, N. Vaupotic and W. Weissflog, Phys. Rev. E, 2006, 74, 021702. 26 (a) A. Eremin, H. Nadasi, G. Pelzl, S. Diele, H. Kresse, W. Weissflog and S. Grande, Phys. Chem. Chem. Phys., 2004, 6, 1290; (b) A. Eremin, M. Floegel, U. Kornek, S. Stern, R. Stannarius, H. Nadasi, W. Weissflog, C. Zhu, Y. Shen, C. S. Park, J. Maclennan and N. Clark, Phys. Rev. $E, 2012,86,051701$.

27 C. Keith, A. Lehmann, U. Baumeister, M. Prehm and C. Tschierske, Soft Matter, 2010, 6, 1704.

28 (a) M. Alaasar, M. Prehm, M. Nagaraj, J. K. Vij and C. Tschierske, Adv. Mater., 2013, 25, 2186; (b) M. Alaasar, M. Prehm, K. May, A. Eremin and C. Tschierske, Adv. Funct. Mater., 2014, 24, 1703.

29 (a) G. Dantlgraber, U. Baumeister, S. Diele, H. Kresse, B. Lühmann, H. Lang and C. Tschierske, J. Am. Chem. Soc., 2002, 124, 14852; (b) C. Keith, R. Amaranatha Reddy, M. Prehm, U. Baumeister, H. Kresse, J. L. Chao, H. Hahn, H. Lang and C. Tschierske, Chem.-Eur. J., 2007, 13, 2556; (c) Y. Zang, U. Baumeister, C. Tschierske, M. J. O'Callaghan and C. Walker, Chem. Mater., 2010, 22, 2869.

30 C. L. Folcia, J. Ortega, J. Etxebarria, S. Rodriguez-Conde, G. Sanz-Enguita, K. Geese, C. Tschierske, V. Ponsinet, P. Barois, R. Pindak, L. D. Pan, Z. Q. Liu, B. K. McCoyh and C. C. Huang, Soft Matter, 2014, 10, 196.

31 C. Tschierske, Angew. Chem., Int. Ed., 2013, 52, 8828. 